\title{
Biochemical and NMR analyses of an SF3b155-p14- U2AF-RNA interaction network involved in branch point definition during pre-mRNA splicing
}

\author{
ROBERTA SPADACCINI, ${ }^{1}$ ULRICH REIDT, ${ }^{2}$ OLEXANDR DYBKOV, ${ }^{2}$ CINDY WILL, ${ }^{2}$ \\ RONALD FRANK, ${ }^{3}$ GUNTER STIER, ${ }^{1}$ LORENZO CORSINI, ${ }^{1}$ MARKUS C. WAHL, ${ }^{2}$ \\ REINHARD LÜHRMANN, ${ }^{2}$ and MICHAEL SATTLER ${ }^{1}$ \\ ${ }^{1}$ European Molecular Biology Laboratory Heidelberg, D-69117 Heidelberg, Germany \\ ${ }^{2}$ Max-Planck-Institute for Biophysical Chemistry, Department Cellular Biochemistry, D-37077 Göttingen, Germany \\ ${ }^{3}$ Department of Chemical Biology, Gesselschaft für Biotechnologische Forschung (GBF), D-38124 Braunschweig, Germany
}

\begin{abstract}
The 14 subunit of the essential splicing factor $3 b$ (SF3b) can be cross-linked to the branch-point adenosine of pre-mRNA introns within the spliceosome. p14 stably interacts with the SF3b subunit SF3b155, which also binds the 65-kDa subunit of U2 auxiliary splicing factor (U2AF65). We combined biochemical and NMR techniques to study the conformation of p14 either alone or complexed with SF3b155 fragments, as well as an interaction network involving p14, SF3b155, U2AF65, and U2 snRNA/premRNA. p14 comprises a canonical RNA recognition motif (RRM) with an additional C-terminal helix $(\alpha C)$ and a $\beta$ hairpin insertion. SF3b155 binds to the $\beta$-sheet surface of p14, thereby occupying the canonical RNA-binding site of the p14 RRM. The minimal region of SF3b155 interacting with p14 (i.e., residues 381-424) consists of four $\alpha$-helices, which are partially preformed in isolation. Helices $\alpha 2$ and $\alpha 3$ (residues 401-415) constitute the core p14-binding epitope. Regions of SF3b155 binding to p14 and U2AF65 are nonoverlapping. This allows for a simultaneous interaction of SF3b155 with both proteins, which may support the stable association of U2 snRNP with the pre-mRNA. p14-RNA interactions are modulated by SF3b155 and the RNA-binding site of the p14-SF3b155 complex involves the noncanonical $\beta$ hairpin insertion of the p14 RRM, consistent with the $\beta$-sheet surface being occupied by the helical SF3b155 peptide and p14 helix $\alpha$ C. Our data suggest that p14 lacks inherent specificity for recognizing the branch point, but that some specificity may be achieved by scaffolding interactions involving other components of SF3b.
\end{abstract}

\section{INTRODUCTION}

The accurate removal of introns from eukaryotic premRNAs is mediated by a large ribonucleoprotein (RNP) complex called the spliceosome (Burge et al. 1999). In the first catalytic step of splicing the $2^{\prime}$ hydroxyl of the branch point, adenosine carries out a nucleophilic attack on the $5^{\prime}$ splice-site phosphate, generating a free $5^{\prime}$ exon and the intron- $3^{\prime}$ exon in the form of a lariat structure. In the subsequent step, the $3^{\prime}$ hydroxyl of the $5^{\prime}$ exon attacks the

Reprint requests to: Michael Sattler, European Molecular Biology Laboratory Heidelberg, Meyerhofstrasse 1, D-69117 Heidelberg, Germany; e-mail: sattler@embl.de; fax: 49 (0)6221 387-306; or Reinhard Lührmann, Max-Planck-Institute for Biophysical Chemistry, Department Cellular Biochemistry, Am Fassberg 11, D-37077 Göttingen, Germany; e-mail: reinhard.luehrmann@mpi-bpc.mpg.de; fax: 49 (0)551-201-1197.

Article and publication are at http://www.rnajournal.org/cgi/doi/ 10.1261/rna.2271406. $3^{\prime}$ splice site leading to intron release and ligation of the $3^{\prime}$ and $5^{\prime}$ exons.

The major (U2-dependent) spliceosome is formed via the ordered interaction of U1, U2, U5, and U4/U6 snRNPs (small nuclear RNPs) and numerous splicing factors with RNA elements located at the $5^{\prime}$ and $3^{\prime}$ ends of a pre-mRNA intron (Burge et al 1999). The minor U12-dependent spliceosome catalyzes splicing of relatively rare U12-type introns that are found only in some metazoans and is formed by the ordered interaction of the U11/U12, U4atac/U6atac, and U5 snRNPs (Patel and Steitz 2003).

While splicing catalysis occurs in the so-called $\mathrm{C}$ complex, the splice-site elements are initially recognized at the onset of spliceosome assembly. During formation of the initial E complex, U1 snRNP binds to the $5^{\prime}$ splice site. The $3^{\prime}$ splice-site elements are recognized by cooperative binding of splicing factors to cognate RNA sequences. Specifically, the large and small subunits of U2AF (U2 snRNP 
auxiliary factor; U2AF65 and U2AF35) (Zamore et al. 1992) bind to the polypyrimidine (Py) tract (Zamore et al. 1992; Singh et al. 1995) and the downstream AG dinucleotide, respectively (Zamore et al. 1992; Merendino et al. 1999; Wu et al. 1999; Zorio and Blumenthal 1999). The branch-point sequence (BPS) is recognized by splicing factor 1 (SF1, or mammalian branch point binding protein, $\mathrm{mBBP}$ ) (Krämer 1996; Berglund et al. 1997). Binding of SF1 to the BPS is weak ( $K_{D} \sim 1 \mu M$, (Liu et al. 2001), but its affinity is significantly increased by a simultaneous interaction with the third RNA recognition motif (RRM3) of U2AF65 (Berglund et al. 1998; Selenko et al. 2003).

Subsequently, the U2 snRNP interacts with the branchpoint sequence displacing SF1. In this so-called A complex, a duplex is formed between the BPS and the U2 snRNA. The invariant branch-point adenosine that acts as the nucleophile in the first catalytic step is bulged out in this branch-site helix (Query et al. 1994; Berglund et al. 2001). A phylogenetically conserved pseudouridine in the U2 snRNA, located opposite the branch site, may induce a unique conformation of the branch-point adenosine that primes it for attack at the $5^{\prime}$ splice site (Newby and Greenbaum 2002). In addition, U2AF and several subunits of the U2 snRNP-associated splicing factors (SF) $3 a$ and $3 b$ contact the pre-mRNA near the BPS (Staknis and Reed 1994; Gozani et al. 1996, 1998; Query et al. 1996; Krämer et al. 1999; McPheeters and Muhlenkamp 2003). For example, the 155-kDa subunit of SF3b (SF3b155) can be cross-linked to RNA sequences up- and downstream of the BPS. An Nterminal region in SF3b155 also binds the third RNA recognition motif (RRM) of U2AF65 (Gozani et al. 1998). The U2AF65 RRM3-SF3b155 interaction replaces the U2AF65SF1 interaction and contributes to the recruitment of the U2 snRNP to the branch site (Gozani et al. 1998).

In the minor spliceosome, the U11 and U12 snRNPs form a stable U11/U12 di-snRNP that binds to pre-mRNA during assembly of the minor A complex. U12 snRNA base pairs with the BPS and the branch-point adenosine is also bulged out (Hall and Padgett 1996). Interactions between the U11 snRNP and the $5^{\prime}$ splice site are required to stabilize the U12 branch-site interaction (Frilander and Steitz 1999). As U12-type introns lack a polypyrimidine tract, U2AF does not appear to facilitate association of U12 with the branch site. In contrast, SF3b appears to take part in both splicing pathways, as it is an integral part of both the U2 snRNP and the U11/U12 di-snRNP (Will et al. 1999, 2004).

Together with all other SF3b subunits (i.e., SF3b155, SF3b145, SF3b130, SF3b49, SF3b14b, and SF3b10), SF3b14a/ p14 (denoted p14 hereafter) is present in both the major and minor spliceosomes (Will et al. 1999, 2001, 2004). p14 can be cross-linked to the branch-point adenosine (Query et al. 1997; Will et al. 2001) first after the integration of the U2 snRNP into the major prespliceosome, and at least until the formation of complex C (MacMillan et al. 1994). Thus, p14 is located near the catalytic center responsible for the first catalytic step of the splicing reaction and the presence of p14 in both the minor and major spliceosome suggests a common mechanism of branch-point selection in mammals. Like all other SF3b subunits, p14 is highly conserved among higher eukaryotes (Will et al. 2001), suggesting that it plays an important role in the splicing process.

A cryo-electron microscopic (EM) investigation of isolated SF3b (Golas et al. 2003) indicated that the particle forms a spherical structure with a hollow interior. It was suggested that p14 is located inside the central cavity, where it would be largely inaccessible to the branch-point adenosine. However, the EM structure of the U11/12 di-snRNP, which contains SF3b (Golas et al. 2005), revealed a more open conformation of SF3b, suggesting that it may undergo a conformational rearrangement that makes p14 accessible for pre-mRNA interaction.

Previous studies revealed a tight interaction between p14 and SF3b155, and roughly mapped the region of human SF3b155 that contacts p14 to amino acids 255-424 (Will et al. 2001). Intriguingly, this region also includes residues mediating SF3b155's interaction with U2AF65 (Gozani et al. 1998). Here, we have analyzed the conformation of p14 alone or complexed with a fragment of SF3b155 using NMR. In addition, we have defined the p14/SF3b155 interaction interface and the binding site of SF3b155 with U2AF65 using NMR and peptide scanning experiments. Finally, we have studied the binding of p14 alone, or as part of either a p14/SF3b155 heterodimer or the entire SF3b complex, with the pre-mRNA BPS, U2 snRNA, or duplexes thereof. These studies delineate the protein and RNA interaction network involving p14, and thus provide insights into molecular interactions near the catalytic core of the spliceosome.

\section{RESULTS}

\section{Analysis of the interaction between p14 and SF3b155}

\section{Residues 381-424 of SF3b155 constitute a minimal binding epitope for $p 14$}

Previous GST pull-down experiments have demonstrated that a region comprising residues $255-424$ in the N-terminal region of SF3b155 preceding its HEAT repeats binds to p14 (Will et al. 2001) (cf. Fig. 1). We found that SF3b155 ${ }^{1-459}$ can be coexpressed and copurified with p14 through a series of affinity and ion-exchange chromatographic steps (data not

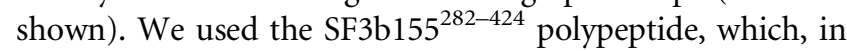
contrast to other subfragments, could be expressed and purified also in the absence of p14, to determine the binding affinity of SF3b155 and p14. Using isothermal titration calorimetry, a dissociation constant $\left(\mathrm{K}_{\mathrm{D}}\right)$ of $9.6 \mathrm{nM}$ was determined with a $1: 1$ p14-SF3b155 $5^{282-424}$ stoichiometry, 
A SF3b155

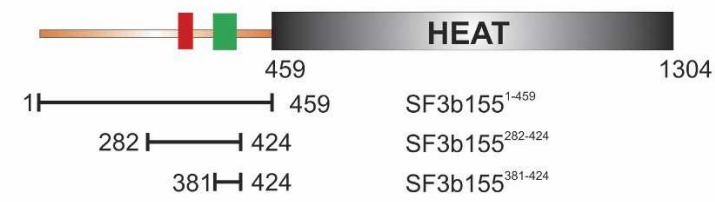

B $\mathrm{p} 14$

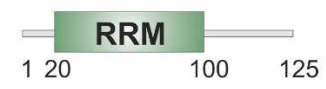

\section{U2AF65}

\section{RRM1}

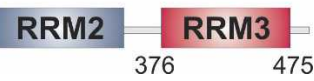

FIGURE 1. SF3b155, p14, and U2AF65 domain composition. Domain composition and protein fragments used for NMR and biochemical experiments for $(A)$ SF3b155, $(B)$ p14, and $(C)$ U2AF65.

indicating a strong enthalpically driven interaction between SF3b155 and p14 (Table 1).

The EM structure of the native SF3b complex does not provide any information about the structure of the $\mathrm{N}$ terminal region of SF3b155, while the C-terminal HEAT repeats could be clearly visualized (Golas et al. 2003). Secondary structure predictions (http://bip.weizmann.ac. il/fldbin/findex) suggest that the entire $\mathrm{N}$-terminal region of SF3b155 (residues 1-459) could be largely unstructured. We therefore reasoned that p14 could recognize short, linear peptide epitopes within the SF3b155 N-terminal portion and used NMR titrations and peptide scan experiments to map the binding epitope.

In order to define residues within SF3b that participate in the binding interface with p14, we analyzed NMR spectra of ${ }^{15} \mathrm{~N}$-labeled SF3b155 upon addition of p14 (Fig. 2A). Within the SF3b155 ${ }^{282-424}$ region, only NMR signals of residues 380-424 are affected by the interaction with p14 (Fig. 2B). Moreover, the NMR signals of a ${ }^{15} \mathrm{~N}$-labeled 43 residue SF3b $155^{381-424}$ peptide that is bound to p14 are very similar to the corresponding residues within the SF3b155 $5^{282-424}$-p14 complex, indicating identical binding interfaces (Fig. 2A). We next monitored changes in ${ }^{1} \mathrm{H},{ }^{15} \mathrm{~N}$ correlation NMR spectra of ${ }^{15} \mathrm{~N}$-labeled p14 upon addition of unlabeled SF3b155 $5^{282-424}$ (Fig. 3A). As expected, large chemical-shift changes confirm the tight interaction of SF3b155 with p14. Likewise, the addition of the SF 3 b $155^{282-424}$ or SF3b $155^{381-424}$ peptides to ${ }^{15} \mathrm{~N}$-labeled p14 affects the same set of residues in p14, and the resulting spectra are very similar (Fig. 3A). These data demonstrate that the 43 -residue SF3b155 ${ }^{381-424}$ fragment contains all determinants required for p14 binding.

Additional evidence mapping the p14-SF3b155 interaction interface was obtained by performing peptide scanning experiments. An array of overlapping 20-mer peptides covering amino acids 258-424 of SF3b155 was chemically synthesized and tested for binding to p14. In vitro translated p14, labeled with $\left[{ }^{35} \mathrm{~S}\right]$ methionine, bound strongly to four consecutive peptides of the array representing amino acids 395-421 of SF3b155. The smallest peptide fragment common to all four peptides is ${ }^{402}$ EELDAMFPEGYKVL ${ }^{415}$ (Fig. 2C). Notably, these residues experience the largest chemical-shift perturbation upon addition of p14 to SF $3 b 155^{381-424}$, indicating that this region comprises an important part of the interface.

\section{SF3b155 $5^{381-424}$ adopts an $\alpha$-helical conformation that is partially induced upon p14 binding}

We assigned the ${ }^{1} \mathrm{H},{ }^{15} \mathrm{~N}$ and ${ }^{13} \mathrm{C}$ backbone chemical shifts of the SF3b155 $5^{282-424}$ fragment using standard methods (Sattler et al. 1999). The ${ }^{13} \mathrm{C} \alpha$ and ${ }^{13} \mathrm{C} \beta$ secondary chemical shifts in the free SF $3 b 155^{282-424}$ peptide indicate two helical regions between residues 381-391 (helix $\alpha 1$ ) and 401-406 ( $\alpha 2$ ) (Fig. 2B). Upon binding to p14, a helical conformation is further induced for residues $410-414(\alpha 3)$ and residues $419-423(\alpha 4)$ as indicated by the ${ }^{13} \mathrm{C} \alpha$ secondary chemical shifts (Fig. 2B). Thus, the NMR data show that the p14-binding epitope of SF3b155 adopts a conformation comprised of four helices, of which helix $\alpha 1$ and $\alpha 2$ are preformed, while helices $\alpha 3$ and $\alpha 4$ are induced upon binding to p14. The core binding motif (residues 401-415) is mainly helical and comprises helices $\alpha 2$ and $\alpha 3$.

\section{Secondary structure and a homology model of the p14 RRM}

p14 is a highly conserved 125-residue protein. Primary sequence signatures indicate that the protein contains an RNA recognition motif (RRM) (Will et al. 2001). We have assigned the NMR resonances of almost all backbone atoms of the p14 RRM in isolation. The flanking $\mathrm{N}$ - (residues 120) and C-terminal regions (residues 100-125) are unstructured, and only partial chemical-shift assignments could be obtained due to signal overlap and line broadening. The analysis of the ${ }^{13} \mathrm{C}$ secondary chemical shifts, $\Delta \delta(\mathrm{C} \alpha-\mathrm{C} \beta)$, confirms the expected $\beta 1-\alpha \mathrm{A}-\beta 2-\beta 3-\alpha \mathrm{B}-\beta 4$ topology of

TABLE 1. Isothermal titration calorimetry

\begin{tabular}{lcccc}
\hline & $\mathrm{K}_{\mathrm{d}}$ & $\Delta \mathrm{H}\left[\mathrm{kcal} \mathrm{mol}^{-1}\right]$ & $\Delta \mathrm{S}\left[\mathrm{cal} \mathrm{K}^{-1}\right.$ mol $\left.^{-1}\right]$ & Stoichiometry $(\mathrm{n})$ \\
\hline SF3b155 & $9.6 \mathrm{nM}$ & -12.70 & -6.1 & 1.00 \\
SF3b155 & -1.13 & -14.61 & 1.05 \\
\hline
\end{tabular}


A

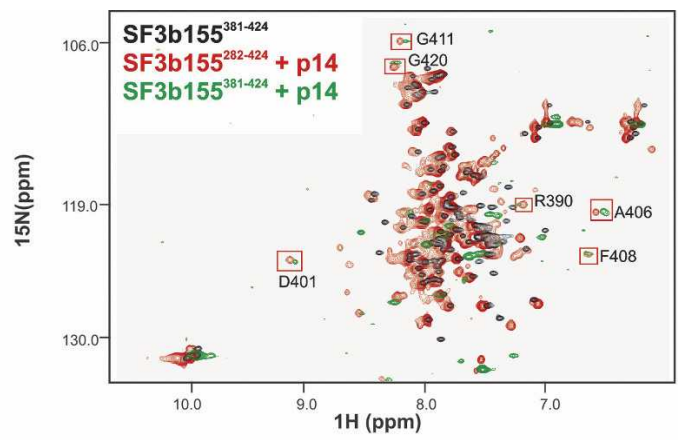

$\mathbf{B}$

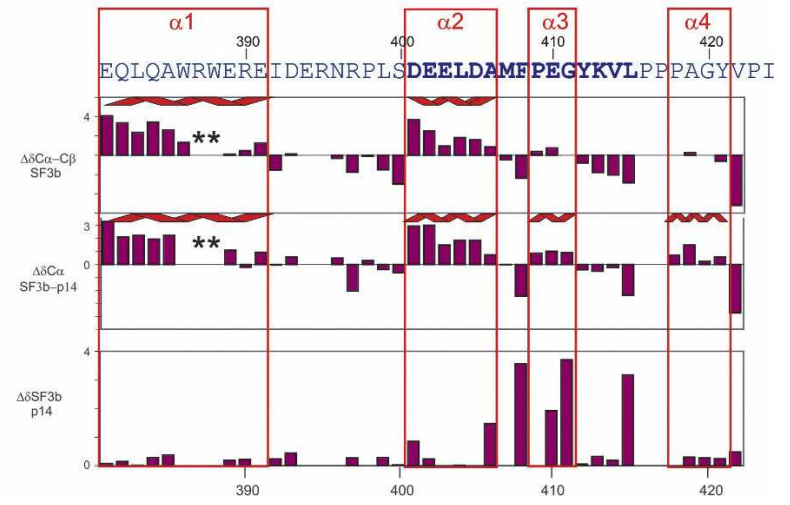

C

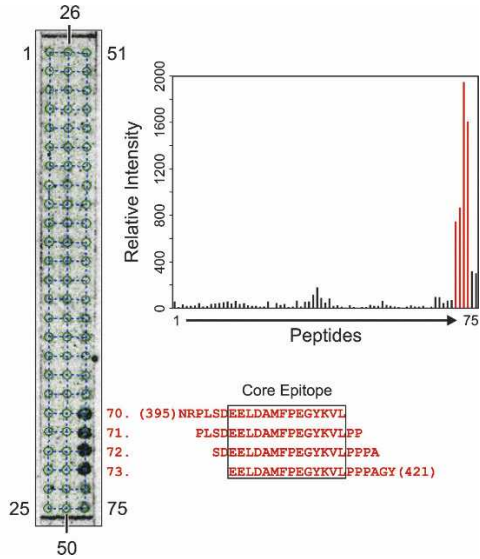

FIGURE 2. Secondary structure and p14 binding site of SF3b155. (A) ${ }^{1} \mathrm{H}^{15}{ }^{15}$ correlation spectrum of ${ }^{15} \mathrm{~N}-$ labeled SF $3 \mathrm{~b}^{282-424}$ (black) and in the presence of unlabeled p14 (red). ${ }^{1} \mathrm{H},{ }^{5} \mathrm{~N}$ correlation spectrum of SF3b ${ }^{381-424}$ after addition of p14 (green). Addition of p14 to SF3b ${ }^{282-424}$ or $\mathrm{SF} 3 \mathrm{~b}^{381-424}$ affects the same set of residues in both spectra. Residues with large chemical-shift perturbations belong to the minimal binding epitope for the p14 interaction and are boxed in red. $(B){ }^{13} \mathrm{C}$ secondary chemical shifts of free SF3b155 $282-424$ and when bound to p14 (row 1 and 2 ), and chemical-shift perturbation of SF3b155 $5^{282-424}$ upon addition of p14. Secondary structure elements are indicated on top. (C) Peptide scan analysis of the SF3b155-p14 interaction. (Left) Autoradiogram obtained by incubating the cellulose-bound peptide array with $\left[{ }^{35} \mathrm{~S}\right] \mathrm{methionine-labeled}$ p14. Peptide numbers for the terminal spots are indicated. Sequences for peptides 70-73, which constitute the central binding epitope of SF3b155 for p14, are indicated in red (starting and ending residue numbers in parentheses). (Right) Bar graph of the quantified relative affinities of the SF3b155 peptides $1-75$ toward p14 (represented by the radioactivity at each spot). The response of the peptides 70-73, comprising the central binding epitope, is shown in red.

the canonical RRM fold (Fig. 3B). Notably, this fold is extended by an additional $\beta$ hairpin ( $\left.\beta 3^{\prime}-\beta 3^{\prime \prime}\right)$ between helix $\alpha \mathrm{B}$ and $\beta 4$, and the p14 RRM also comprises a short C-terminal helix $\alpha \mathrm{C}$ (A97-K100). A helix C exists only in few RRM structures, where it usually packs against the $\beta$ sheet surface. In the U1A RRM1 domain, helix $\alpha \mathrm{C}$ can move away in order to allow RNA binding by the RNP motif residues in the center of the $\beta$ sheet (Maris et al. 2005). On the basis of the secondary NMR chemical shifts, which define the secondary structure elements, and a sequence alignment with the U1A RRM (39\%/56\% sequence identity/homology), we generated a homology model of the p14 RRM (Fig. 3C).

\section{Mapping the SF3b155-binding site on the structural model of $p 14$}

NMR titrations of p14 with SF3b155 were analyzed to map the chemical-shift perturbations observed upon SF3b155 binding onto the structural model of the p14 RRM (Fig $6 \mathrm{~A}$, below). The most pronounced chemical-shift changes are observed for residues located at the $\beta$-sheet surface. Most notably, residues within the RNP1 and RNP2 motifs are strongly affected by the addition of the SF3b155 $282-424$ peptide. In addition, residues in the $\beta 1-\alpha \mathrm{A}$ and the $\alpha \mathrm{A}-\beta 2$ loops experience large chemical-shift changes upon SF3b155 binding (Fig. 3B). Based on the secondary ${ }^{13} \mathrm{C}$ chemical shifts of free and bound p14, the secondary structure of p14 is not altered by binding of SF3b155 (Fig. 3B). Specifically, the C-terminal helix $\alpha \mathrm{C}$ is present in both free and SF3b155-bound p14.

A surprising observation is that the $\beta$-sheet surface, including residues in the RNP1 and RNP2 motifs, which mediate RNA binding in canonical RRMs, forms the binding interface with the SF3b155 peptide. This indicates that-in addition to helix $\alpha \mathrm{C}$-the helical SF3b155 peptide (presumably helices $\alpha 2$ and $\alpha 3$ within the core binding motif) binds to the $\beta$-sheet surface, and thus renders RNP1 and RNP2 motif residues inaccessible for RNA binding. Therefore, RNA binding of the p14 RRM either would require a conformational rearrangement where the helical SF3b155 peptide and helix $\alpha \mathrm{C}$ move away from the $\mathrm{p} 14 \beta$-sheet surface or involves a different site of the p14 RRM. To clarify this question, we next investigated the RNA-binding properties of $\mathrm{p} 14$ and the p14-SF3b155 complex. 
A

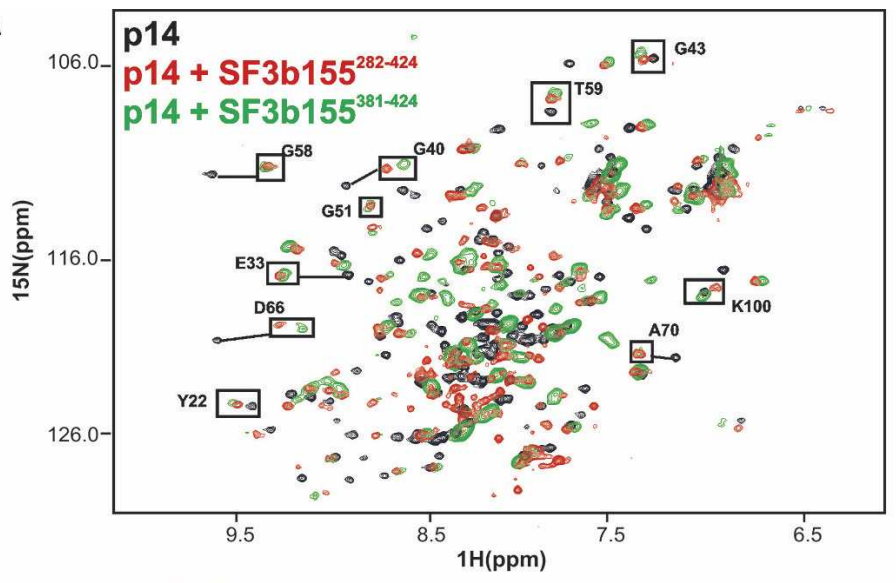

C

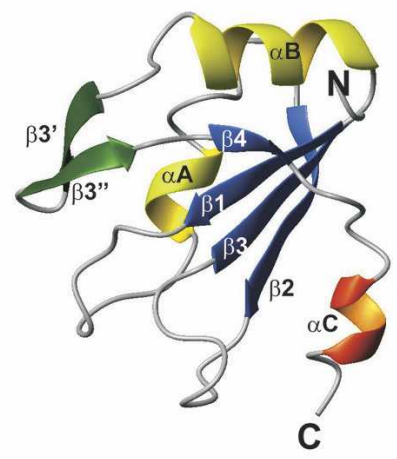

B

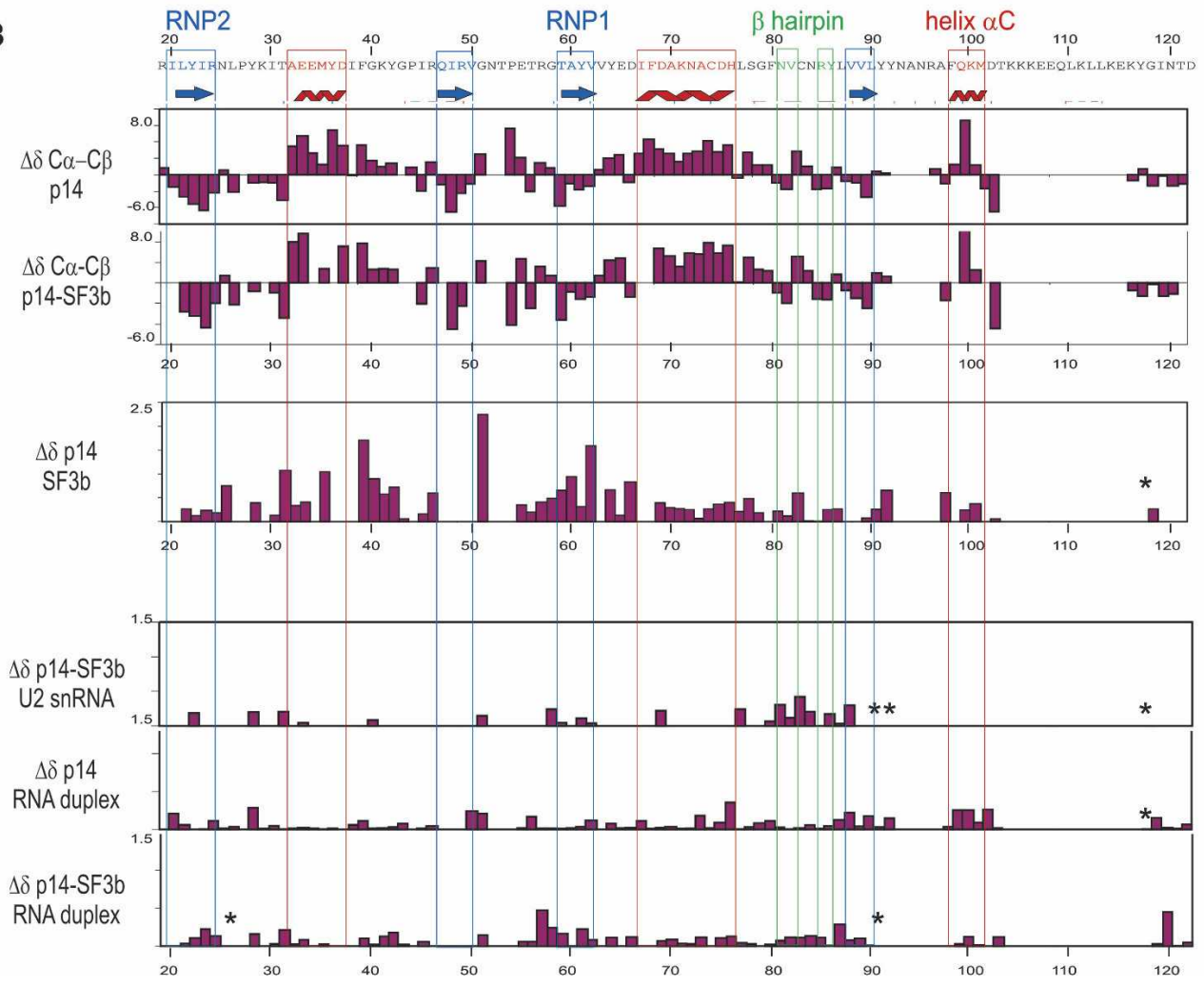

FIGURE 3. Secondary structure and binding site of p14 with SF3b155 and RNA. $(A){ }^{1} \mathrm{H},{ }^{15} \mathrm{~N}$ correlation NMR spectra of ${ }^{15} \mathrm{~N}$-labeled p14 alone (black) and in the presence of unlabeled SF3b ${ }^{282-424}$ (red) or SF3b ${ }^{381-424}$ (green). Both SF3b peptides induce very similar effects on p14 as indicated for some residues (black boxes). $(B){ }^{13} \mathrm{C}$ secondary chemical shifts of p14 alone and when bound to SF3b ${ }^{282-424}$. Secondary structure elements are shown on top. Chemical-shift changes of p14 amide groups upon addition of SF3b ${ }^{282-424}$, and chemical-shift perturbation on p14 and p14-SF3b155 $282-424$ upon addition of the U2 oligo and the U2/BPS RNA duplex. ( ${ }^{*}$ ) Signals that are strongly affected but could not be assigned in the bound state. $(C)$ Homology model of p14 based on the secondary NMR chemical shifts and a sequence alignment with the U1A RRM.

\section{RNA binding of p14 and the p14-SF3b155 complex}

UV-induced cross-linking of RNA to p14 and the p14-SF3b155 $5^{282-424}$ complex

As p14 could previously be cross-linked to the branch-point adenosine of the pre-mRNA during splicing (MacMillan et al. 1994; Query et al. 1996), we investigated the RNAbinding properties of p14, fragments of SF3b155, and p14SF3b155 complexes by UV-induced cross-linking or by per- forming electrophoretic gel mobility shift assays (EMSA). The branch-point adenosine of the pre-mRNA is bulged out from a double-helical segment formed by the premRNA BPS and a short stretch of U2 snRNA that exhibits sequence complementarity with the U2-type BPS, respectively (Query et al. 1994; Berglund et al. 2001) (Fig. 4B). We thus investigated the interaction of the p14 and SF3b155 with single-stranded RNA oligonucleotides comprising the region of the human U2 snRNA that binds the BPS, 
A

\begin{tabular}{|c|c|c|}
\hline Oligo & Sequence & Description \\
\hline $\mathrm{u} 2$ & CGG UGU AGU AUC G & $\begin{array}{l}\text { Branch point interacting } \\
\text { region of } U 2 \text { snRNA }\end{array}$ \\
\hline $\mathrm{U} 2 \Psi$ & 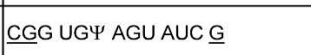 & $\begin{array}{l}\text { Branch point interacting } \\
\text { region of U2 snRNA }\end{array}$ \\
\hline U2.BS & CGA UAC UAACAC CG & U2-type BPS \\
\hline U12 & CGG AGU AAG GAG C & $\begin{array}{l}\text { Branch point interacting } \\
\text { region of U12 snRNA }\end{array}$ \\
\hline U12. BS & GCU CCU UGA CUC CG & U12-type BPS \\
\hline DNA & GGC CAT ATG CAC CAT CAT C & Unrelated DNA \\
\hline
\end{tabular}

B U2 $\quad 5^{\prime} \underline{\mathrm{CGG} U G U \mathrm{AGU} A U C \mathrm{G}} 3^{\prime}$ U2.BS 3 '

U12 5' CGG AG UAAG GAGC $3^{\prime}$ U12.BS $3^{\prime} \underline{G C C U C}{ }_{A} G U U C$ CUCG $5^{\prime}$

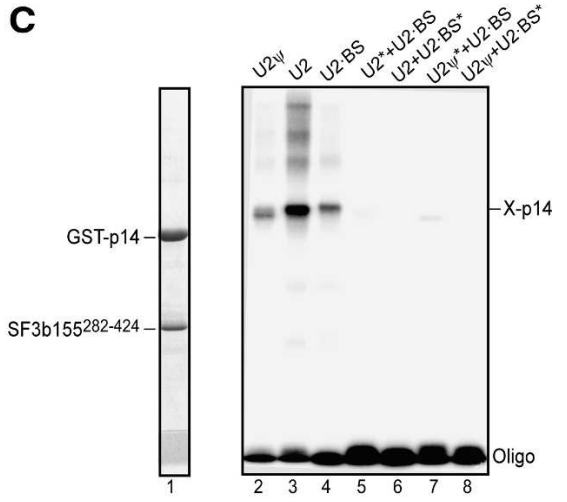

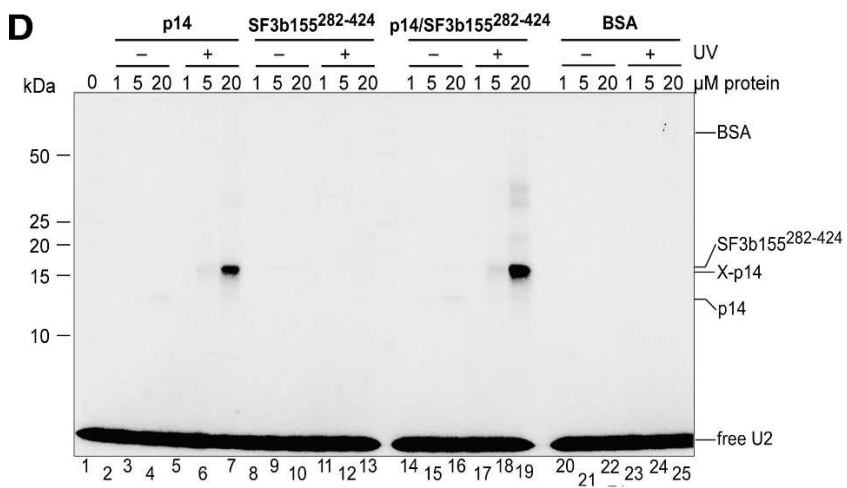

E

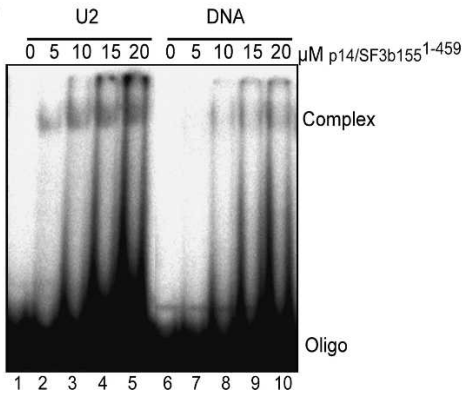

$\mathbf{F}$

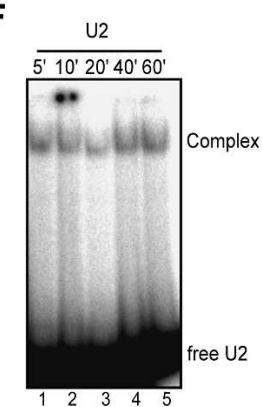

FIGURE 4. RNA cross-linking and gel-shift assays of p14 and p14-SF3b155. (A) Sequence and description of RNA and DNA oligonucleotides. Additional nucleotides added to stabilize duplex formation are underlined. The branch point adenosine is shown in bold. (B) Duplexes formed by oligonucleotides shown in A. (C) UV cross-linking of p14-SF3b $155^{282-424}$. RNP complexes were formed on the oligonucleotides or their duplexes (as indicated above the lanes). Following UV-irradiation, samples were separated on 12\% SDS-PAGE and stained with Coomassie blue (lane 1) or visualized by autoradiography (lanes 2-8). The position of noncross-linked (input) proteins is indicated on the left and that of oligonucleotides and the RNA-p14 cross-link are indicated on the right. Duplexes contained only one ${ }^{32} \mathrm{P}$-labeled oligonucleotide, which is marked by an asterisk $\left.{ }^{*}\right)$. Note that in this experiment, the p14 protein contained a GST tag. (D) UV-cross-linking of p14, SF3b $155^{282-424}$, or p14-SF3b155 ${ }^{282-424}$ to the $\mathrm{U} 2$ oligonucleotide. Increasing concentrations of protein (as indicated above each lane) were incubated with ${ }^{32} \mathrm{P}$-labeled U2 oligonucleotide and were either analyzed directly without UV irradiation (lanes $2-4,8-10,14-16,20-22$ ) or subjected to UV irradiation (lanes 5-7, 11-13, 17-19, 2325 ) and analyzed as in C. BSA (lanes 20-25) was used as a control. (E) EMSA of the p14-SF3b155 ${ }^{1-459}$ complex with oligonucleotides. Increasing concentrations of the p14-SF3b155 ${ }^{1-459}$ protein complex (as indicated above each lane) were incubated with ${ }^{32} \mathrm{P}-$ labeled U2 snRNA oligo (lanes $1-$ 5) or unrelated DNA oligonucleotide (DNA) (lanes 6-10), separated on a native gel, and visualized by autoradiography. $(F)$ Time course of U2 oligo-p14-SF3b ${ }^{1-459}$ complex formation. p14-SF3b155 ${ }^{1-459}$ was incubated with ${ }^{32} \mathrm{P}$-labeled U2 oligo for the indicated time and RNP complex formation was analyzed as in $E$.

or oligos containing a consensus U2-type BPS, as well as U2-BPS duplexes (Fig. 4A,B). The human U2 snRNA contains numerous post-transcriptionally modified residues, among which the pseudouridine at position 34 is of particular interest, as it may induce a unique structure in the
U2-BPS duplex (Newby and Greenbaum 2002). We therefore tested both unmodified and pseudouridine-containing U2 snRNA mimics. Radiolabeled RNA oligomers or duplexes were incubated with proteins or protein complexes, exposed to $254 \mathrm{~nm}$ UV light, and cross-linked pro- 
teins were analyzed by SDS-PAGE followed by autoradiography (Fig. 4C,D).

When cross-linking was performed with a recombinant GST-p14-SF3b155 ${ }^{282-424}$ complex, cross-links were observed between p14 and single-stranded U2 snRNA (both with and without pseudouridine) or single-stranded U2type BPS RNA (Fig. 4C, lanes 2-4). p14 alone, but not SF3b155 $5^{282-424}$, could be cross-linked to the U2 snRNA oligomer lacking pseudouridine (Fig 4D, cf. lanes 5-7 and 11-13). The cross-linking efficiency was lower with isolated p14 compared with p14 complexed with SF3b155 $5^{282-424}$ (cf. lanes 5-7 and 17-19). In contrast, no cross-link was observed between the U2-BPS duplex RNA, either with p14,

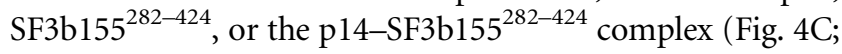
data not shown).

In order to further test the specificity of the p14RNA interactions, we examined cross-linking of a p14SF $3 b 155^{1-459}$ complex, in which the entire $\mathrm{N}$ terminus of SF3b155 is present. Both the U2 snRNA oligomer and an unrelated single-stranded DNA oligomer could be crosslinked with similar efficiency to this complex, with crosslinks primarily formed with p14 (data not shown). A lessabundant cross-link of either nucleic acid to the longer SF3b $155^{1-459}$ fragment was also observed (data not shown). Taken together, the above results suggest that p14-SF3b155 complexes exhibit general single-stranded nucleic acid-binding activity and that nucleic acid contacts are mediated primarily through p14. The cross-linking efficiency of nucleic acids to p14 is enhanced when p14 is complexed with SF3b155, and the extended N terminus of SF3b155 could contribute to nucleic acid binding.

\section{RNA interaction of $p 14$ and p14-SF3b155 by}

electrophoretic gel mobility shift assays

UV-induced cross-linking efficiency depends not only on binding affinity, but also on a productive orientation of the cross-linking moieties. Thus, the different conformation of the RNAs when singled-stranded versus in the form of a duplex, could hinder cross-linking to the latter, despite the formation of a protein-RNA complex. Indeed, UV-induced RNA-protein cross-links are typically not formed when nucleotides are engaged in base-pairing interactions. Therefore, we also assayed RNA binding by p14, SF3b155 deletion mutants, or p14-SF3b155 $5^{1-459}$ by performing electrophoretic gel mobility shift assays. Increasing amounts of the aforementioned proteins were incubated with radiolabeled nucleic acids, and complex formation was analyzed on native polyacrylamide gels. SF $3 b 155^{282-424}$ alone did not bind RNA or DNA at the protein concentrations tested (up to $100 \mu \mathrm{M}$ ) (data not shown). In contrast, nucleic acid interactions were detected with p14 and the p14SF3b155 $5^{282-424}$ complex when high concentrations of protein $(100 \mu \mathrm{M})$ were used. However, only very diffuse bands were observed, indicating that the interactions are weak or governed by fast association and dissociation kinetics (data not shown). The binding appeared to be nonspecific, as all of the tested RNA and DNA oligos were bound in both cases (data not shown).

Distinct RNP complexes are, however, observed when EMSA was performed with p14 complexed with SF 3 b $155^{1-459}$ (Fig. 4E). A slightly higher affinity of p14-SF3b $155^{1-459}$ is observed for single-stranded U2 RNA over DNA (Fig. 4E, cf lanes $1-5$ and 6-10). An even weaker interaction is observed with the U2/BPS RNA duplex (data not shown). The amount of complex formed between p14-SF3b155 $5^{1-459}$ and the U2 snRNA oligo does not increase beyond 5 min of incubation (Fig. 4F, lanes 1-5), indicating fast binding and dissociation kinetics of the protein-RNA complexes. Taken together, these results suggest that the interaction of p14 with SF3b155 ${ }^{1-459}$ enhances the nucleic acid-binding capacity of p14, and is consistent with the notion that additional nucleic acid contacts are mediated by the extended $\mathrm{N}$ terminus of SF3b155.

\section{Mapping the RNA-binding surface of p14 and p14/SF3b155}

In order to map the RNA-binding surface of p14 and the p14-SF3b155 complex, we performed NMR titration experiments with the same RNA ligands that were used for cross-linking and gel-shift assays. Numerous chemicalshift changes were observed in the ${ }^{1} \mathrm{H},{ }^{15} \mathrm{~N}$ correlation spectra of p14 after addition of the single-stranded U2 RNA (data not shown). These effects are consistent with nonspecific nucleic acid binding as also observed in the crosslinking and band-shift experiments, and may correlate with the extended positively charged surface of the p14 protein (Fig. 6C, below). Smaller chemical-shift perturbations affecting only a subset of residues were observed upon addition of the U2 snRNA-BPS duplex, indicating a weaker interaction of p14 with the duplex RNA (Fig 5A).

NMR titrations show that also the p14-SF3b155 $5^{282-424}$ complex can bind to both the single-stranded U2 snRNA oligo and to the duplex RNA (Fig. 5B,C). Residues that are affected by the addition of these RNAs precede the RNP1 motif (strand $\beta 3$ ), or are located in the $\beta 3$ ', $\beta 3$ " hairpin, and helix $\alpha \mathrm{C}$ (Figs. 3B, 6B). Notably, the residues in the RNP1 and RNP2 motifs do not experience very strong chemical-shift perturbations. This is in contrast to canonical RRMs, where large chemical-shift perturbations are observed for RNP residues that directly contact the RNA (see, for example, Howe et al. 1998).

A more detailed analysis of the chemical-shift perturbation of residues in p14 upon addition of SF3b15 $5^{282-424}$ and the U2-BPS duplex RNA provides additional insight (Fig. 5DG). Residues located in the RNP1 and RNP2 motifs within the central part of the $\beta$ sheet experience the largest perturbations upon addition of the SF3b155 $5^{282-424}$ peptide, while smaller shifts are observed for these residues upon addition of the RNA duplex to either p14 or the p14-SF3b155 ${ }^{282-424}$ complex (Fig. 5D,E; red arrows). These observations suggest 
that even upon addition of the RNA, the helical SF3b155 peptide remains bound at the $\beta$-sheet surface. In contrast, the NMR signals of residues located in the $\beta 3$ ' $\beta 3$ " hairpin or helix $\alpha \mathrm{C}$ are only weakly affected by the addition of SF3b155 $5^{282-424}$ (Fig. 5F,G), and are mainly shifted by the addition of the RNA duplex to the p14-SF3b155 ${ }^{282-424}$ (Fig. 5F,G; green arrows). Notably, the extent and directionality of the chemical-shift changes observed for these residues upon addition of the RNA duplex to p14-SF3b155 $5^{282-424}$ are very different (Fig. 5F,G; green arrows) compared with the addition of SF3b155 $5^{282-424}$ to p14 (red arrows), and rather small changes are seen upon addition of the RNA duplex to p14 alone (blue arrows).

These data suggest that the binding site of the p14SF3b155 $5^{282-424}$ complex with the RNA involves a region flanking the central $\beta$ sheet, involving mainly the $\beta 3^{\prime}, \beta 3$ " hairpin. Most notably, the RNP residues appear not to be involved in direct RNA interactions. The overall small chemical-shift perturbations indicate a weak interaction and argue against any large conformational changes upon RNA binding. Thus, most likely, helix $\alpha \mathrm{C}$ remains bound at the surface of the $\beta$ sheet, even in the presence of RNA. Thus, the $\beta$-sheet surface, which represents the canonical RNA-binding surface in RRM domains, would be occupied by helix $\alpha \mathrm{C}$ as well as the helical SF3b155 peptide in the p14-SF3b155 complex.

We also tested whether residues of SF3b155 $5^{282-424}$ within the p14-SF3b155 $5^{282-424}$ complex may mediate direct RNA contacts by monitoring spectral changes for residues of ${ }^{15} \mathrm{~N}$-labeled SF3b155 $5^{282-424}$ bound to unlabeled p14 upon addition of the U2 snRNA/BPS RNA duplex. The NMR spectrum of SF3b155 $5^{282-424}$ bound to p14 does not show any additional spectral changes upon addition of the RNA duplex, indicating that SF3b $155^{282-424}$ does not directly contact the RNA (data not shown).

Taken together, the NMR studies indicate that both p14 and the p14-SF3b155 $5^{282-424}$ complex bind weakly and with poor specificity to RNA. Our data show that within the p14-SF3b155 ${ }^{282-424}$ complex, the p14 RRM interacts with the RNA in a noncanonical fashion. The $\beta$-sheet surface of the RRM is occupied by the helical SF3b155 peptide and presumably helix $\alpha \mathrm{C}$, while contacts to the RNA mainly involve the $\beta 3^{\prime} \beta 3^{\prime \prime}$ hairpin. The distinct binding interfaces of the p14 RRM with SF3b155 and RNA are highlighted in Figure 6, A and B.

Binding of the native SF3b particle to single-stranded and double-stranded RNA

Although p14 has been UV cross-linked to the branch site in spliceosomal complexes (MacMillan et al. 1994; Query et al. 1996), we did not detect any cross-links between recombinant p14-SF3b155 complexes and a U2 snRNA/BPS duplex. Thus, it is possible that the nucleic acid-binding properties of p14 are modulated upon its incorporation into the hetero-
A

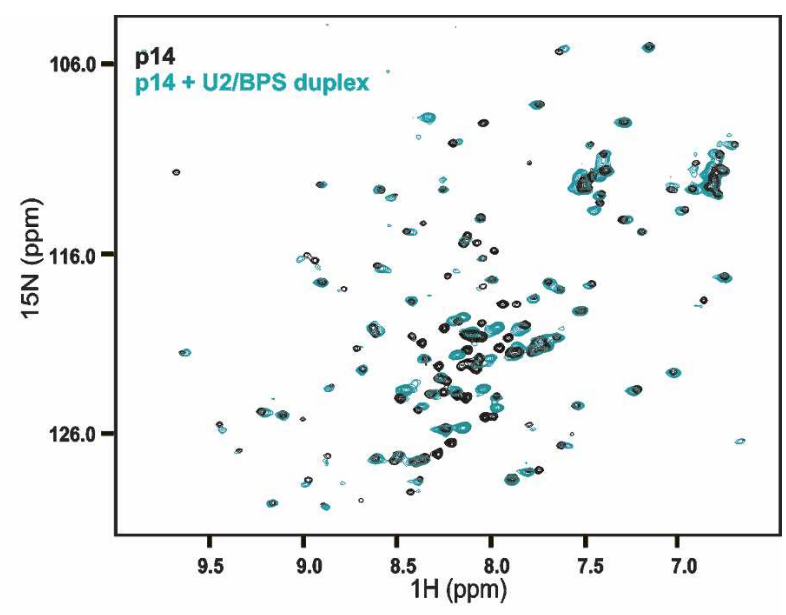

B

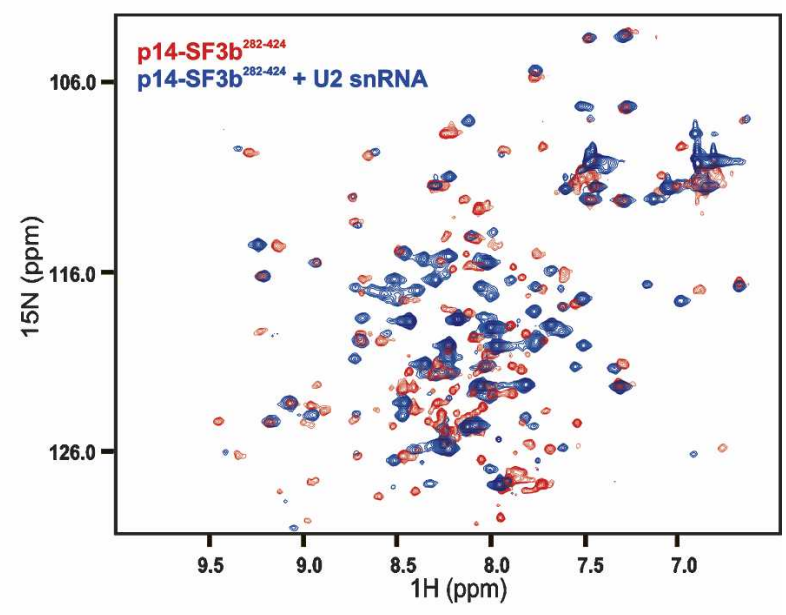

C

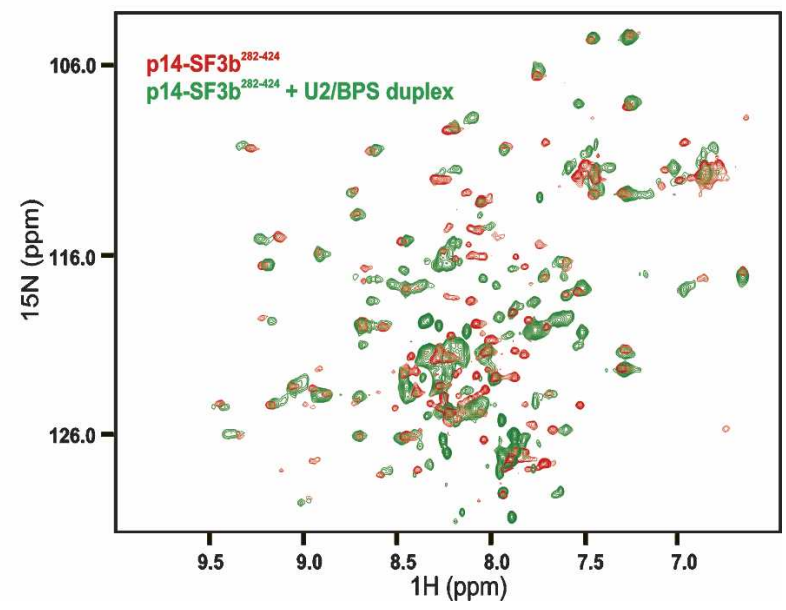

FIGURE 5. (Continued on next page)

meric SF3b protein complex. To test this possibility, we immunoaffinity purified native SF3b complexes from HeLa nuclear extract and assayed for their interaction with several nucleic acids using EMSA and UV cross-linking. In addition to the U2 snRNA and U2-type BPS oligomers and their duplex and a DNA oligomer (DNA) (see Fig. 4A), the following RNAs were tested for SF3b binding: the region of the 


\section{D $\quad$ RNP2}
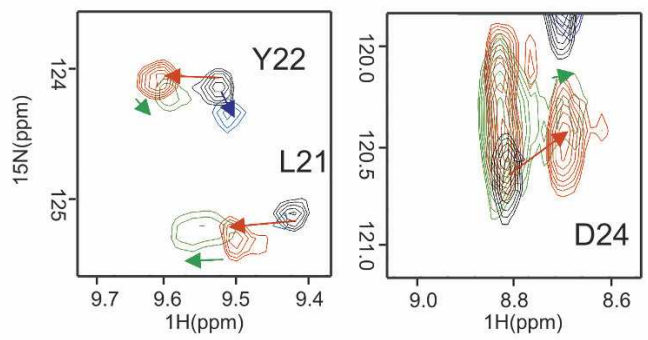

$$
\begin{aligned}
\mathrm{p} 14 \longrightarrow & \mathrm{p} 14+\mathrm{U} 2 / \mathrm{BPS} \text { duplex } \\
& \mathrm{p} 14-\mathrm{SF} 3 \mathrm{~b}^{281-424} \\
& \stackrel{\downarrow}{\mathrm{p} 14-\mathrm{SF}} 3 \mathrm{~b}^{281-424}+\text { U2/BPS duplex }
\end{aligned}
$$

E
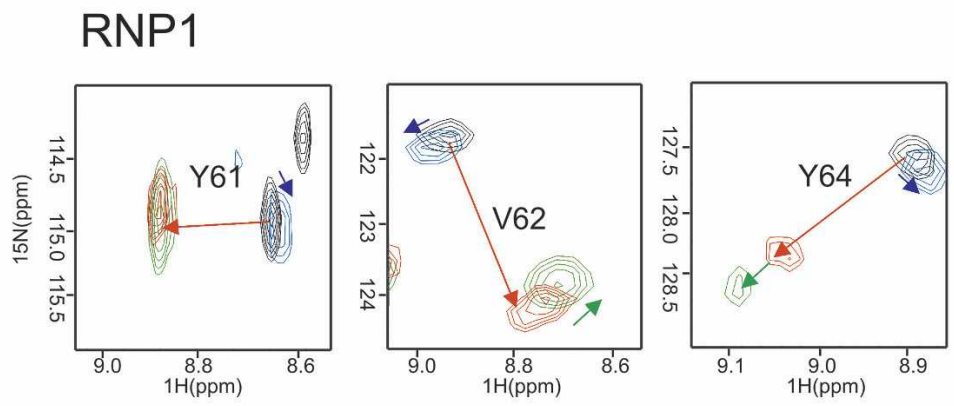

$\mathbf{F}$

$\beta 3$ ', $\beta 3$ " hairpin
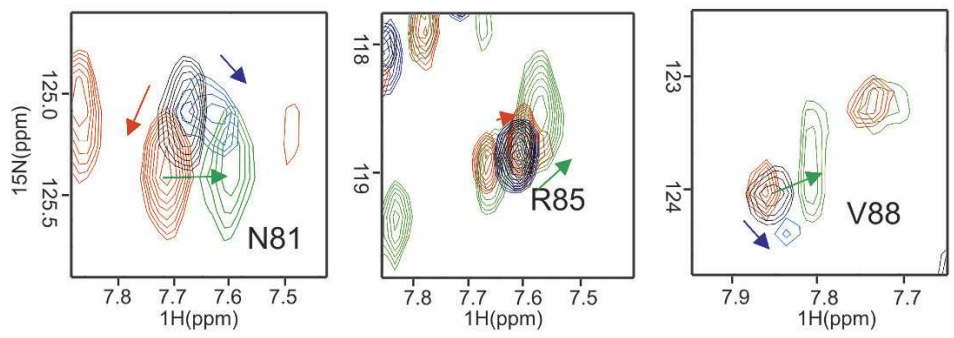

G helix $\alpha \mathrm{C}$

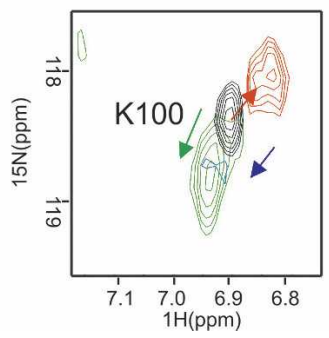

FIGURE 5. NMR RNA titration experiments with p14 and p14-SF3b155. (A) ${ }^{1} \mathrm{H},{ }^{15} \mathrm{~N}$ correlation spectra of ${ }^{15} \mathrm{~N}$-labeled p14 alone (black) and upon addition of the U2/BPS RNA duplex (cyan). (B) ${ }^{1} \mathrm{H},{ }^{15} \mathrm{~N}$ correlation spectra of the p14 $\left({ }^{15} \mathrm{~N}\right.$ labeled)-SF $3 \mathrm{~b} 155^{282-424}$ (unlabeled) complex (red) and upon addition of the single-stranded U2 RNA oligonucleotide (blue) $(C){ }^{1} \mathrm{H},{ }^{15} \mathrm{~N}$ correlation spectrum of the p14 $\left({ }^{15} \mathrm{~N}\right.$ labeled)SF3b155 $5^{282-424}$ (unlabeled) complex (red) alone and upon addition of the U2/BPS RNA duplex (green) (D-G) Enlarged views of the spectra shown in $A-D$ for residues located in RNP2, RNP1, the $\beta 3$ ', $\beta 3$ ” hairpin, and helix $\alpha$ C. Colored arrows show the extent of chemical-shift perturbations between free p14 and the binary and ternary complexes with SF3b155 and the U2/BPS RNA duplex as indicated.

human U12 snRNA that binds the U12-type BPS (U12), the consensus U12-type BPS (U12 BPS), a U12 snRNA-U12type BPS duplex, a 34-mer intronic sequence containing a U2-type BPS and adjacent poly-pyrimidine tract (BPS+PY), an RNA encompassing 19 nucleotides upstream of a U2-type BPS (Anchor), unrelated 21-mer RNAs (RNA1, RNA2, and RNA3), and an unrelated RNA duplex formed between RNA2 and 3 (Fig. 7A).
SF3b did not bind DNA in these experiments, suggesting that, in contrast to the recombinant p14-SF3b155 complexes, the native SF3b complex preferentially binds RNA over DNA (Fig. 7B, lane 30). In the presence of RNA, a slower and faster migrating complex was observed, which could reflect different SF3b conformations. The faster migrating complex formed on all single-stranded RNAs tested (Fig. 7B), including the unrelated RNAs 1, 2, and 3, suggesting that SF3b exhibits general 
A

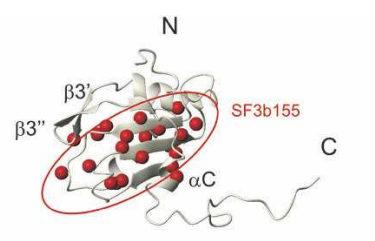

B

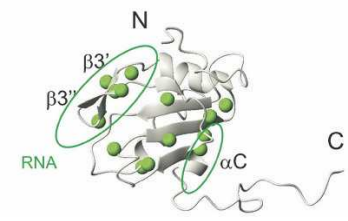

$90^{\circ} y$

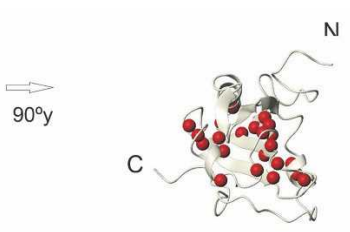

C

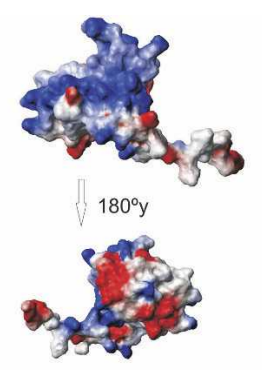

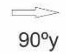

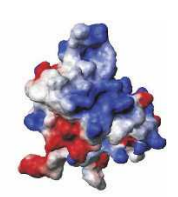

FIGURE 6. Binding site of p14 with SF3b155 and RNA. (A) Ribbon representation of the homology model of p14. Red balls indicate amides of residues with large chemical-shift perturbations upon binding to SF3b155 ${ }^{282-424}$. The SF3b155-binding site is circled. $(B)$ Residues of p14 in the p14-SF3b155 ${ }^{282-424}$ complex, which are affected by the addition of the U2/BPS RNA duplex are indicated by green balls. The main RNA-binding site is highlighted. (C) Surface representation of the p14 homology model, shown in the same orientation as in $A$ and $B$, colored by electrostatic surface potential. The surface was calculated with MOLMOL (Koradi et al. 1996).

RNA-binding activity. Formation of this complex was considerably weaker with the U2 snRNA/BPS RNA duplex or did not form at all in the case of the U12 snRNA/BPS (Fig. 7B, lane 18) and control duplexes (lane 28). A distinct, slower migrating complex was efficiently formed with the U2-type BPS RNA (Fig. 7B, lanes 6,20), but only weakly with most of the other RNAs tested. A double band was observed with the 34mer intronic sequence containing a U2-type BPS and adjacent polypyrimidine tract (Fig. 7B, lane 8). The upper band could be similar to the slower migrating complex observed with the U2-type BPS alone, the difference in migration behavior resulting from the larger size of the BPS+PY oligomer.

To determine which subunits of SF3b contact RNA or DNA, UV-induced cross-linking analyses were performed. Similar to results obtained with recombinant p14 or p14 complexed with an N-terminal fragment of SF3b155, p14 within the SF3b complex appeared to be cross-linked to the U2 snRNA oligomer and U2-type BPS RNA (Fig. 7C, lanes 7-8). The U2-type BPS RNA was also additionally crosslinked to SF3b155 (lane 8). This observation is consistent with the notion that the extended $\mathrm{N}$ terminus of SF3b155 might mediate additional RNA contacts (see above). Furthermore, the fact that SF3b155 was efficiently crosslinked solely to the U2-type BPS RNA is in agreement with the more efficient formation of a distinct, slower migrating SF3b-RNA complex in the gel-shift experiments upon addition of this RNA (see above). Of the remaining SF3b subunits, only SF3b49, which contains two RNA recognition motifs, was clearly cross-linked to the single-stranded but not duplex RNAs tested (Fig. 4C, cf. lanes 7-11). In addition, a strong cross-link between SF3b49 and DNA (but not other SF3b components) was observed (Fig 4C, lane 9). However, as no DNA-SF3b complexes were observed in our gel-shift assays, this likely represents a relatively weak interaction. Taken together, these results suggest that puri- fied SF3b exhibits general RNA binding, with some preference for U2-type branch-point sequences.

\section{Interaction of SF3b155 and U2AF65}

A region comprising residues $267-369$ of SF3b155 has previously been shown to mediate its interaction with RRM3 of U2AF65 (Gozani et al. 1998). Based on the three-dimensional structures of the U2AF65 RRM3 (Selenko et al. 2003) and the U2AF35 RRM (Kielkopf et al. 2001) bound to short peptides, a consensus sequence for ligands of these atypical RRMs could be deduced. This consensus consists of an $\mathrm{X}-[\mathrm{R} / \mathrm{K}]-\mathrm{W}$ tripeptide preceded by a stretch of positively charged amino acids. Within the $\mathrm{N}$ terminus of SF3b155, a number of such sequence motifs can be identified, which could potentially mediate binding to the U2AF65 RRM3. We therefore performed NMR-binding studies to identify which residues within SF3b155 $5^{282-424}$ mediate the interaction with U2AF65 RRM3, and to test whether the SF3b155-binding epitopes for U2AF65 and p14 overlap.

Upon addition of unlabeled U2AF65 RRM3 to ${ }^{15} \mathrm{~N}$ labeled SF3b155 $5^{282-424}$, a limited number of residues were affected (Fig. 8A). Notably, all of these residues precede the p14-binding epitope and large chemical-shift perturbations are observed for residues 331-346 (Fig. 8C). The subsequent addition of p14 to the SF3b155-U2AF65 RRM3 complex does not alter the signals that are affected by the addition of U2AF65 RRM3 (Fig. 8B). Moreover, the chemical perturbations observed upon addition of p14 to the SF3b155-U2AF65 RRM3 complex (Fig. 8B,D) are virtually indistinguishable from the effects induced by addition of p14 to SF3b155 $5^{282-424}$ alone (cf. Fig. 2A). In ITC experiments, the binding affinity of a 40-residue fragment SF3b155 $5^{317-357}$ to U2AF65 RRM3 is $K_{D}=6.3 \mu \mathrm{M}$ (Table 1). Thus, the affinity between this fragment of SF3b155 and 
A

\begin{tabular}{|l|l|l|}
\hline Oligo & Sequence & Description \\
\hline BPS+PY & $\begin{array}{l}\text { GGG UGCUGAC UGG CUU CUU CUC } \\
\text { UCU UUU UCC CUC }\end{array}$ & $\begin{array}{l}\text { Intronic BPS and PPT of } \\
\text { PIP85.B pre-mRNA }\end{array}$ \\
\hline Anchor & CGA UGU CAG CUC GUC UCG A & $\begin{array}{l}\text { Intronic RNA upstream of } \\
\text { BPS of PIP85.B pre-mRNA }\end{array}$ \\
\hline RNA1 & AAU GGG AGU ACC AAC AUA UdTdT & Unrelated RNA \\
\hline RNA2 & GAG GAU CUA GGA GAA ACC CdTdT & Unrelated RNA \\
\hline RNA3 & GGG UUU CUC CUA GAU CCU CdTdT & Unrelated RNA \\
\hline
\end{tabular}

B

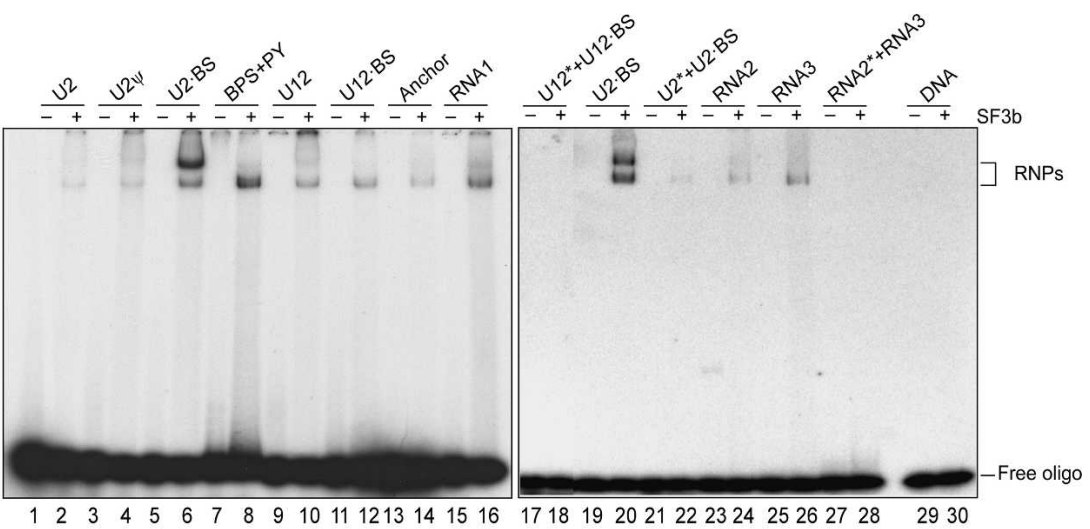

C

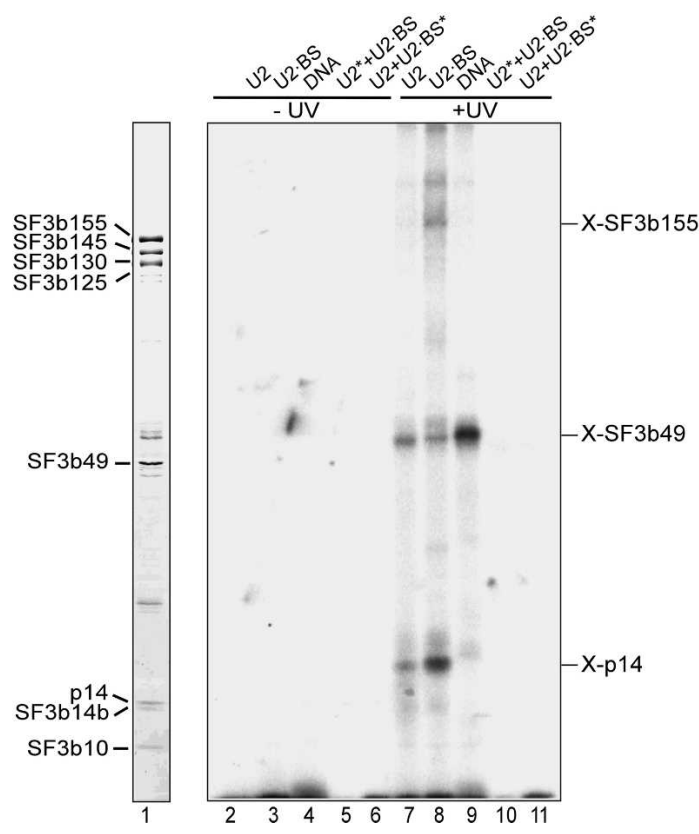

FIGURE 7. Binding of nucleic acids to the native SF3b particle. (A) Sequence and description of additional RNA oligonucleotides used in binding studies. (B) EMSA of native SF3b protein complexes with oligonucleotides or their duplexes. The various single- or double-stranded oligonucleotides (indicated above each lane) were incubated without (odd-numbered lanes) or with SF3b (even-numbered lanes) and analyzed as in Figure 4E. Duplexes contained only one ${ }^{32} \mathrm{P}$-labeled oligonucleotide that is marked by an asterisk. (C) UV-cross-linking of the native SF3b complex. SF3b was incubated with single- or double-stranded oligonucleotides (indicated above each lane) and nonirradiated samples (lanes 1-6) or UV-irradiated samples (lanes 7-11) were analyzed by SDSPAGE and visualized by autoradiography (lanes $2-10$ ) or by Coomassie blue staining (lane 1). The position and apparent identity of RNA-protein cross-links are indicated on the right.

U2AF65 RRM3 is smaller compared with the interaction with p14. This is also consistent with the significantly smaller chemical-shift perturbations observed in the NMR titration of the larger fragment SF3b155 $5^{282-424}$ with U2AF65
RRM3 (Fig. 8, cf. C and D). Only one ligand consensus motif for binding to U2AF65 RRM3 is present between residues 317 and 357 in SF3b155, indicating that this KSRW ${ }^{338}$ motif strongly contributes to the binding affinity. Taken together, these data show that the consensus motif encompassing $\operatorname{Trp}^{338}$ of human SF3b155 mediates the U2AF65 interaction and that this region is nonoverlapping with SF3b155's p14 binding site. Our findings are thus compatible with the simultaneous binding to p14 and U2AF65 to SF3b155.

\section{DISCUSSION}

\section{Structural features of the p14- SF3b155 interface}

We studied the interaction of the spliceosomal p14 and SF3b155 proteins using biochemical and NMR techniques and analyzed their interaction with single-stranded RNAs comprising an intron branch-point sequence or the branch-site interacting region of U2 snRNA, as well as a branch-site RNA duplex formed by these oligonucleotides. NMR analyses demonstrated that p14 comprises an RRM domain, extended by a central $\beta$ hairpin and a C-terminal helix $\alpha \mathrm{C}$, which is only found in a subset of RRM folds. We further showed that p14 interacts tightly with SF3b155 and that the binding interface involves the $\beta$-sheet surface of the p14 RRM fold. A 43-residue peptide $\left(\mathrm{SF} 3 \mathrm{~b}^{381-424}\right)$ in the $\mathrm{N}$-terminal part of SF3b155 defines a minimal binding epitope for $\mathrm{p} 14$, in which residues 401-415 constitute a core binding motif. NMR data revealed that the SF3b155 peptide binds to the p14 RRM in an $\alpha$-helical conformation, which is partly preformed in the isolated SF3b155 protein.

\section{Weak RNA binding to a noncanonical site of the p14 RRM}

Based on available three-dimensional structures of other RRMs, the C-terminal helix $\alpha \mathrm{C}$ of p14 presumably packs on top of the $\beta$-sheet surface, which is normally involved in RNA interaction in canonical RRM domains (Fig. 6). Addi- 


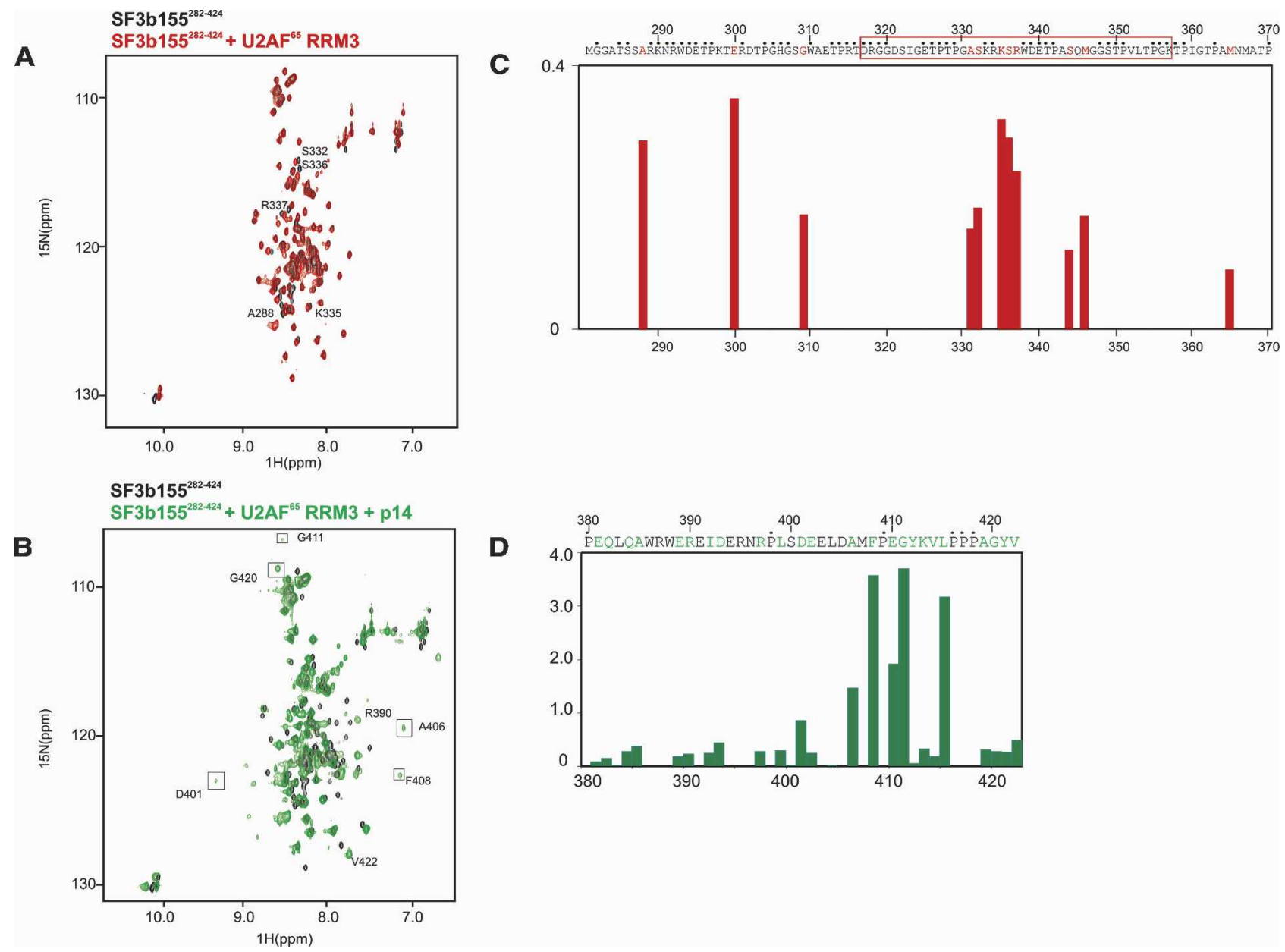

FIGURE 8. Interaction of SF3b155, U2AF65, and p14. (A) ${ }^{1} \mathrm{H},{ }^{15} \mathrm{~N}$ correlation spectrum of ${ }^{15} \mathrm{~N}$-labeled SF3b155 ${ }^{282-424}$ (black) and after addition of U2AF65 RRM3 (red). (B) ${ }^{1} \mathrm{H},{ }^{15} \mathrm{~N}$ correlation spectrum of ${ }^{15} \mathrm{~N}$-labeled SF3b155 ${ }^{282-424}$ when bound to U2AF65 RRM3 (black) and after addition of p14 (green). (C) Chemical-shift perturbation for the amide signals of SF3b155 $5^{282-424}$ upon addition of U2AF65 RRM3. Residues that could not be assigned in the N-terminal region of SF3b155 are marked by a dot. (D) Chemical-shift perturbation for the amide signals of SF3b155 ${ }^{282-424}$ upon addition of p14. Residues that could not be assigned in the N-terminal region of SF3b155 are marked by a dot.

tionally, a helical region in SF3b155 binds to the $\beta$ sheet surface as indicated by the strongest chemical-shift perturbations for residues located in RNP1 ( $\beta 3$ ). Thus, the RRM $\beta$ sheet in the p14-SF3b155 complex is most likely inaccessible for RNA binding. Consistent with this notion, the NMR chemical-shift perturbations map the binding site with RNA ligands to a region flanking the RRM $\beta$ sheet. While SF3b155 binding induces the largest chemical-shift changes in residues within RNP1 and RNP2, RNA binding mainly affects residues in the $\beta 3^{\prime} \beta 3^{\prime \prime}$ hairpin, especially in the p14SF3b155 complex. Some caution is advised in the interpretation of the chemical-shift perturbation, since a priori it is not possible to distinguish between chemical shifts induced by direct RNA contacts and indirect effects, which may reflect small conformational changes upon RNA binding. It is possible that the small chemical-shift perturbations observed for residues in RNP1/2 motifs and helix $\alpha \mathrm{C}$ upon addition of RNA to the p14-SF3b155 complex (see Fig. 6B) reflect a combination of direct contacts and indirect effects. For exam- ple, direct contacts with the RNA at the $\beta 3^{\prime}, \beta 3$ " hairpin may slightly affect the conformation of the SF3b 155 peptide and helix $\alpha \mathrm{C}$, resulting in small chemical-shift changes of residues in helix $\alpha \mathrm{C}$. Only few NMR signals could be analyzed for the unstructured regions flanking the RRM N- and C-terminally. Consistent with the NMR-binding data, UV cross-linking and gel-shift experiments indicated that both p14 and the complex of p14 with either SF3b155 $5^{282-424}$ or SF3b $b^{1-459}$ bind only weakly and with little sequence specificity to singlestranded U2 snRNA or BPS RNA oligonucleotides and to duplexes formed between them.

\section{RNA interaction of the p14-SF3b155 complex and SF3b}

Taken together, the RNA-binding data show that p14 alone or complexed with SF3b $155^{282-424}$ or SF3b $155^{1-459}$ interacts weakly and nonspecifically with nucleic acids. However, NMR data suggest that the binding interface of the p14- 
SF3b155 complex with a U2 snRNA/BPS RNA duplex is distinct and more localized. Neither cross-linking experiments nor NMR-binding studies indicate that the SF3b155 $5^{282-424}$ peptide engages in direct contacts with RNA. Nevertheless, RNA binding monitored by gel-shift experiments was improved when using a protein complex comprising the entire $\mathrm{N}$ terminus of SF3b155 (p14SF3b $155^{1-459}$ ). Moreover, RNA cross-links to SF3b155 were observed in the context of the native SF3b particle purified from HeLa cell nuclear extracts and also with the p14-SF3b155 $5^{1-459}$ complex. These data suggest that some additional nucleic acid contacts ensue through the extended $\mathrm{N}$ terminus of SF3b155, which may explain the observed improvement in RNA-binding affinity. In contrast to the p14-SF3b155 ${ }^{1-459}$ complex, the isolated SF3b particle did not bind DNA, suggesting that additional SF3b components or a different conformation of p14 and/or SF3b155 within this complex enhances RNA-binding specificity. Interestingly, p14 RNA cross-links were observed not only with p14 (or p14 complexed with SF3b155), but also with p14 within purified SF3b complexes. Previous EM studies suggested that p14 is located inside the central cavity of SF3b, where it would be largely inaccessible to the branch-point adenosine (Golas et al. 2003). Our data suggest that some regions of p14 may be accessible to RNA (at least to short oligoribonucleotides), even when p14 is complexed with all other subunits of SF3b.

\section{p14 does not specifically recognize a U2 snRNA/BPS RNA duplex}

Maybe the most surprising finding is that neither p14 nor the p14-SF3b155 complex recognize the branch-point RNA helix with high affinity and specificity. As p14 can be crosslinked to the branch-point adenosine during several steps of the pre-mRNA splicing process, from complex A to complex C (Query et al. 1997; Will et al. 2001), it might have been expected that p14 is able to specifically recognize the branch-point helix on its own or when complexed with SF3b155, its main interacting partner. We also found no evidence for improved binding affinity or specificity for a branch-point helix containing a pseudouridine-modified U2 snRNA, likewise indicating that there is no specific recognition of a bulged-out branch-point adenosine. Furthermore, isolated SF3b complexes also failed to recognize the branch-point RNA helix with high affinity and specificity. The apparently higher affinity for a singlestranded U2-type branch point sequence suggests that SF3b components, including p14, could potentially recognize the BPS prior to U2 snRNA base-pairing interaction and thus facilitate U2/BPS duplex formation. It is also possible that the association of SF3b with the U2 snRNP is accompanied by conformational changes in the p14SF3b155 complex that impart enhanced branch-point helix-binding specificity on the proteins. Indeed, EM stud- ies indicate that SF3b undergoes a significant conformational change upon association with the U11/U12 disnRNP (Golas et al. 2005). On the other hand, p14 may simply be positioned at the BPS via the interaction of the U2 snRNP with this region of the pre-mRNA. In particular, additional pre-mRNA contacts involving other SF3b proteins as seen in our cross-linking experiments could restrain the BPS such that the branch-point adenosine is appropriately held in place for binding by p14.

\section{Simultaneous binding of SF3b155 to p14 and U2AF65 in complex $\mathrm{A}$}

The interaction between U2AF65 and SF3b155 is essential for the recruitment of the U2 snRNP to the branch site (Gozani et al. 1998). We have shown that SF3b155 binds to the third RRM of U2AF65 in vitro, and that this interaction can occur simultaneously with the p14-SF3b155 interaction. Thus, U2AF65, when bound to the Py tract near the $3^{\prime}$-splice site of an intron, can recruit the U2 snRNP via binding to SF3b. The binding surfaces on U2AF65 for SF1 and SF3b155 proteins both involve RRM3 (Gozani et al. 1998) and are most likely structurally similar (Selenko et al. 2003). This suggests that the displacement of SF1 from RRM3 of U2AF65 upon transition of complex E to complex A may contribute to the stable integration of the U2 snRNP into the spliceosome. Interestingly, the region of SF3b155, which interacts with U2AF65 exhibits a number of potential phosphorylation sites (S/T-P-X). This raises the possibility that the U2AF/SF3b interaction might be regulated by phosphorylation.

\section{MATERIALS AND METHODS}

\section{Recombinant protein production}

A p14 expression construct has been described previously (Will et al. 2001). The expression level of p14 from this construct was variable, especially in labeling experiments. To get reliable yields, the gene was recloned into a modified pET24d vector including a GST carrier and a PreScission protease cleavage site. DNA fragments coding for SF3b155 fragments (SF5b-155 ${ }^{1-459}$, SF3b155 $5^{282-424}$,

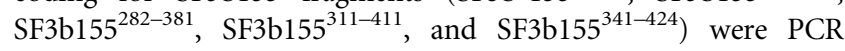
amplified from a human cDNA library and inserted via NcoI and Acc65I restriction sites into the expression vector pETM11 (EMBL). These proteins were produced as N-terminally $\mathrm{His}_{6}$-tagged variants with the tags removable via TEV protease cleavage. Transformed bacterial cultures were propagated in selective LB medium, induced by the addition of $1 \mathrm{mM}$ IPTG, and maintained at $20^{\circ} \mathrm{C}$ overnight before harvesting.

Proteins were initially captured on glutathione-Sepharose beads (p14) or Ni-NTA resin (SF3b155 fragments). After affinity purification, tags were removed by PreScission or TEV protease cleavage. Proteins or complexes were further purified by anion exchange chromatography and gel filtration. Target fractions were identified by SDS-PAGE, pooled concentrated by ultrafil- 
tration, and stored at $-80{ }^{\circ} \mathrm{C}$ after flash-freezing in liquid nitrogen.

SF5b-155 $5^{1-459}$ and SF3b155 $5^{282-424}$ were either purified alone or in complex with p14. Other SF3b155 fragments were only produced in complex with p14. For complex production, Escherichia coli cells were transformed with both respective expression vectors. After coexpression, the complexes were copurified, making use of both affinity tags and sequential cleavage by the proteases.

\section{Peptide array binding experiments}

In order to delineate the minimal fragment of SF3b155 capable of interacting with p14, we synthesized overlapping 20-mer peptides (18-residue overlap) that covered the entire 258-424 region of human SF3b155. The N-terminally acetylated peptides were assembled as an array of spots tethered by their C-termini to a specially modified ACS-01 cellulose membrane (AIMS Scientific Products GmbH) as described (Frank and Overwin 1996). p14 was cloned into pETM10 (EMBL) via NcoI and Acc65I restriction sites and the $\mathrm{N}$-terminally $\mathrm{His}_{6}$-tagged protein was produced by in vitro transcription/translation using rabbit reticulocyte lysate and $\left[{ }^{35} \mathrm{~S}\right]$ methionine. The peptide array was incubated with the radiolabeled p14 translate, washed as described (Niebuhr et al. 1997), and bound p14 was visualized by autoradiography. The image was scanned with a white light scanner at $300 \mathrm{dpi}$ and analyzed with Phoretix Array software. Integration of circular areas from the centers of the spots yielded the relative binding affinities shown in Figure 2C.

\section{Isothermal titration calorimetry}

Thermodynamic parameters for complex formation between p14 and SF3b155 $5^{282-424}$ were extracted from isothermal titration calorimetry (ITC) experiments on two MCS-ITC Instruments (MicroCal) at $25^{\circ} \mathrm{C}$. Purified protein preparations were adjusted to concentrations of $0.23 \mathrm{mM}$ (p14), $0.005 \mathrm{mM}$ (SF3b155 $5^{282-424}$ ), $0.032 \mathrm{mM}$ (U2AF65), and $0.294 \mathrm{mM}\left(\mathrm{SF} 3 \mathrm{~b} 155^{317-357}\right)$. For the SF3b155-p14 interaction, heat releases following 11 injections of p14 of $8 \mu \mathrm{L}$ each into $1.374 \mathrm{~mL}$ of SF3b155 $5^{282-424}$ were recorded. For the SF3b155-U2AF65 RRM3 interaction, binding heats following 19 injections of SF3b155 $5^{317-357}$ of $15 \mu \mathrm{L}$ each into 1.414 $\mathrm{mL}$ of U2AF65 were measured. The data were analyzed with Microcal Origin 5.0 to extract the enthalpies and entropies of binding $\left(\Delta \mathrm{H}_{\mathrm{a}}\right.$ and $\Delta \mathrm{S}_{\mathrm{a}}$, respectively), the equilibrium dissociation constants $\left(\mathrm{K}_{\mathrm{D}}\right)$ and the interaction stoichiometries $(\mathrm{n})$. In control experiments, no heat release was detectable during similar injections of protein or buffer into plain buffer.

\section{UV-induced cross-linking of oligoribonucleotides to p14, p14/SF3b155 ${ }^{282-424}$ and purified SF3b}

RNA and DNA oligomers for interaction studies were chemically synthesized in-house or obtained from MWG, respectively. Ten-microliter reactions of preassembled purified protein complex p14-SF3b155 $5^{282-424}(85 \mu \mathrm{M})$ or increasing concentrations $(1,5$, and $20 \mu \mathrm{M})$ of p14, SF3b155 $5^{282-424}$, p14-SF3b155 $5^{282-424}$, or BSA were incubated in binding buffer (20 mM Tris- $\mathrm{Hcl}$ at $\mathrm{pH} 6.8,40 \mathrm{mM} \mathrm{NaCl}, 2 \mathrm{mM}$ DTT, $0.1 \mathrm{~g} /$
L tRNA) with radiolabeled oligonucleotides or preformed duplexes $(0.1 \mu \mathrm{M})$ at $20^{\circ} \mathrm{C}$ for $30 \mathrm{~min}$. Ten-microliter reactions containing purified SF3b complex $(\sim 0.1 \mu \mathrm{M})$ and radioactively labeled oligos or duplexes in buffer $(20 \mathrm{mM}$ HEPES-KOH at $\mathrm{pH} 7.9,100 \mathrm{mM} \mathrm{NaCl}, 1.5 \mathrm{mM} \mathrm{MgCl}_{2}, 5 \%$ glycerol, $0.1 \mathrm{~g} / \mathrm{L}$ tRNA, $0.5 \mathrm{mM}$ DTT, $0.5 \mathrm{mM}$ PMSF) were incubated at $15^{\circ} \mathrm{C}$ for $20 \mathrm{~min}$. Samples were subjected to UV irradiation at $254 \mathrm{~nm}$ for $2 \mathrm{~min}$ on a glass slide at $4^{\circ} \mathrm{C}$. Crosslinks were analyzed by SDS-PAGE and visualized by autoradiography.

\section{Electrophoretic mobility shift assays of the p14-SF3b155 ${ }^{1-459}$ complex}

Increasing amounts of $\mathrm{p} 14-\mathrm{SF} 3 \mathrm{~b} 155^{1-459}$ protein complex (5-20 $\mu \mathrm{M})$ were incubated with ${ }^{32} \mathrm{P}$-labeled oligonucleotides in binding buffer containing $120 \mathrm{mM} \mathrm{NaCl}$ at $15^{\circ} \mathrm{C}$ for $20 \mathrm{~min}$ or the times indicated (see Results). Samples were separated on native $6 \%$ polyacrylamide gels (with acrylamide to bis-acrylamide ratio of $80: 1)$ and visualized by autoradiography.

\section{Purification and nucleic acid binding of native SF3b complexes}

Anti-SF3b155 monoclonal antibodies against peptide EQYDPFAEHRPPKIA (positions 99-113 of SF3b155) were obtained from GBF. The affinity-purified antibodies reacted specifically with the SF3b155 protein on Western blots.

Native SF3b complex was purified from HeLa cell nuclear extract using the anti-SF3b155 monoclonal antibodies covalently coupled to protein A Sepharose essentially as described previously (Will et al. 2001). Native SF3b was incubated in buffer $(20 \mathrm{mM}$ HEPES-KOH at $\mathrm{pH} 7.9,100 \mathrm{mM} \mathrm{NaCl}, 1.5 \mathrm{mM} \mathrm{MgCl}_{2}, 5 \%$ glycerol, $0.1 \mathrm{~g} / \mathrm{L}$ tRNA, $0.5 \mathrm{mM}$ DTT, $0.5 \mathrm{mM}$ PMSF) with radioactively labeled oligos or duplexes on ice for $1 \mathrm{~h}$ or at $15^{\circ} \mathrm{C}$ for 20 min. Complexes formed were analyzed on $4 \%$ native polyacrylamide gels and visualized by autoradiography.

\section{NMR spectroscopy and resonance assignments}

For NMR studies, expression of p14, SF3b $155^{282-424}$, and SF3b155 $5^{381-424}$ was performed as described above, except that isotope labeling was obtained by expression in minimal medium containing $\left[\mathrm{U}_{-}{ }^{13} \mathrm{C}\right]$-Glucose and/or ${ }^{15} \mathrm{NH}_{4} \mathrm{Cl}$ as sole carbon and nitrogen sources. The recombinant proteins were purified separately as described above and dissolved in a buffer comprising 20 $\mathrm{mM}$ phosphate buffer, $100 \mathrm{mM} \mathrm{NaCl}$, and $2 \mathrm{mM}$ DTT. NMR experiments were performed at $22^{\circ} \mathrm{C}$ with Bruker DRX600 or DRX500 spectrometers equipped with triple-resonance cryogenic probes and pulsed field gradients. Data were processed with NMRPIPE (Delaglio et al. 1995) and analyzed using NMRVIEW (Johnson and Blevins 1994). Chemical-shift assignments were obtained from standard three-dimensional triple resonance experiments recorded on ${ }^{15} \mathrm{~N},{ }^{13} \mathrm{C}$-labeled samples of p14 and SF3b155 ${ }^{282-242}$ (Sattler et al. 1999). For NMR-binding experiments, typically unlabeled protein or nucleic acid ligands were added to ${ }^{15} \mathrm{~N}$-labeled p14 or SF3b155 peptides, and chemicalshift changes were monitored in two-dimensional ${ }^{1} \mathrm{H},{ }^{15} \mathrm{~N}$ correla- 
tion spectra. Chemical-shift perturbations are calculated as $\left.\left[\Delta \delta^{1} \mathrm{H}\right)^{2}-\Delta \delta\left({ }^{15} \mathrm{~N}\right)^{2}\right]^{1 / 2}$.

\section{Homology modeling}

A homology model of the p14 RRM was calculated with the program MODELLER (Marti-Renom et al. 2000) based on a sequence alignment with the N-terminal RRM domain of U1A. The crystal structure of the U1A RRM1 (PDB accession 1FHT) was used as template since it has a high sequence similarity with the p14 RRM and shares the same secondary structure based on the secondary chemical shifts of the p14 RRM, including a $\beta 3$ ', $\beta 3$ " hairpin and a helix $\alpha C$. Structures and surfaces are displayed using MOLMOL (Koradi et al. 1996).

\section{ACKNOWLEDGMENTS}

We thank S. Daenicke (GBF, Braunschweig, Germany) for expert help in peptide array synthesis and J. Wehland and C. Erck (GBF, Braunschweig, Germany) for help in generating monoclonal antibodies against SF3b155. R.S. is grateful for a long-term EMBO fellowship. This work was supported by grant Lu 294/12-2 from the Deutsche Forschungsgemeinschaft (DFG) to R.L. and the Max-Planck-Society. M.S. acknowledges support from the DFG, the European Commission (FSG-V-RNA), and EMBL.

Received October 25, 2005; accepted November 28, 2005.

\section{REFERENCES}

Berglund, J.A., Chua, K., Abovich, N., Reed, R., and Rosbash, M. 1997. The splicing factor BBP interacts specifically with the pre-mRNA branchpoint sequence UACUAAC. Cell 89: 781-787.

Berglund, J.A., Abovich, N., and Rosbash, M. 1998. A cooperative interaction between U2AF65 and mBBP/SF1 facilitates branchpoint region recognition. Genes \& Dev. 12: 858-867.

Berglund, J.A., Rosbash, M., and Schultz, S.C. 2001. Crystal structure of a model branchpoint-U2 snRNA duplex containing bulged adenosines. RNA 7: 682-691.

Burge, C.B., Tuschl, T., and Sharp, P.A. 1999. Splicing of precursors to mRNAs by the spliceosomes. In The RNA World, 2d ed. (R.F. Gesteland et al., eds), pp. 525-560. Cold Spring Harbor Laboratory Press, Cold Spring Harbor, NY.

Delaglio, F., Grzesiek, S., Vuister, G., Zhu, G., Pfeifer, J., and Bax, A. 1995. NMRPipe: A multidimensional spectral processing system based on UNIX Pipes. J. Biomol. NMR 6: 277-293.

Frank, R. and Overwin, H. 1996. SPOT synthesis. Epitope analysis with arrays of synthetic peptides prepared on cellulose membranes. Methods Mol. Biol. 66: 149-169.

Frilander, M.J. and Steitz, J.A. 1999. Initial recognition of U12-dependent introns requires both U11/5' splice-site and U12/branchpoint interactions. Genes \& Dev. 13: 851-863.

Golas, M.M., Sander, B., Will, C.L., Lührmann, R., and Stark, H. 2003. Molecular architecture of the multiprotein splicing factor SF3b. Science 300: 980-984.

- 2005. Major conformational change in the complex SF3b upon integration into the spliceosomal U11/U12 di-snRNP as revealed by electron cryomicroscopy. Mol. Cell 17: 869-883.

Gozani, O., Feld, R., and Reed, R. 1996. Evidence that sequenceindependent binding of highly conserved U2 snRNP proteins upstream of the branch site is required for assembly of spliceosomal complex A. Genes \& Dev. 10: 233-243.
Gozani, O., Potashkin, J., and Reed, R. 1998. A potential role for U2AF-SAP 155 interactions in recruiting U2 snRNP to the branch site. Mol. Cell. Biol. 18: 4752-4760.

Hall, S.L. and Padgett, R.A. 1996. Requirement of U12 snRNA for in vivo splicing of a minor class of eukaryotic nuclear pre-mRNA introns. Science 271: 1716-1718.

Howe, P.W., Allain, F.H., Varani, G., and Neuhaus, D. 1998. Determination of the NMR structure of the complex between U1A protein and its RNA polyadenylation inhibition element. J. Biomol. NMR 11: 59-84.

Johnson, B.A. and Blevins, R.A. 1994. NMRView: A computer program for the visualization and analysis of NMR data. J. Biomol. NMR 4: 603-614.

Kielkopf, C.L., Rodionova, N.A., Green, M.R., and Burley, S.K. 2001. A novel peptide recognition mode revealed by the $\mathrm{X}$-ray structure of a core U2AF35/U2AF65 heterodimer. Cell 106: 595-605.

Koradi, R., Billeter, M., and Wüthrich, K. 1996. MOLMOL: A program for display and analysis of macromolecular structures. J. Mol. Graph. 14: 51-55.

Krämer, A. 1996. The structure and function of proteins involved in nuclear pre-mRNA splicing. Annu. Rev. Biochem. 65: 367-409.

Krämer, A., Gruter, P., Groning, K., and Kastner, B. 1999. Combined biochemical and electron microscopic analyses reveal the architecture of the mammalian U2 snRNP. J. Cell. Biol. 145: 1355-1368.

Liu, Z., Luyten, I., Bottomley, M.J., Messias, A.C., HoungninouMolango, S., Sprangers, R., Zanier, K., Krämer, A., and Sattler, M. 2001. Structural basis for recognition of the intron branch site RNA by splicing factor 1 . Science 294: 1098-1102.

MacMillan, A.M., Query, C.C., Allerson, C.R., Chen, S., Verdine, G.L., and Sharp, P.A. 1994. Dynamic association of proteins with the pre-mRNA branch region. Genes \& Dev. 8: 3008-3020.

Maris, C., Dominguez, C., and Allain, F.H. 2005. The RNA recognition motif, a plastic RNA-binding platform to regulate post-transcriptional gene expression. FEBS J. 272: 2118-2131.

Marti-Renom, M.A., Stuart, A.C., Fiser, A., Sanchez, R., Melo, F., and Sali, A. 2000. Comparative protein structure modeling of genes and genomes. Annu. Rev. Biophys. Biomol. Struct. 29: 291-325.

McPheeters, D.S. and Muhlenkamp, P. 2003. Spatial organization of protein-RNA interactions in the branch site- $3^{\prime}$ splice site region during pre-mRNA splicing in yeast. Mol. Cell. Biol. 23: 4174-4186.

Merendino, L., Guth, S., Bilbao, D., Martinez, C., and Valcarcel, J. 1999. Inhibition of msl-2 splicing by Sex-lethal reveals interaction between U2AF35 and the $3^{\prime}$ splice site AG. Nature 402: 838-841.

Newby, M.I. and Greenbaum, N.L. 2002. Sculpting of the spliceosomal branch site recognition motif by a conserved pseudouridine. Nat. Struct. Biol. 9: 958-965.

Niebuhr, K., Ebel, F., Frank, R., Reinhard, M., Domann, E., Carl, U.D., Walter, U., Gertler, F.B., Wehland, J., and Chakraborty, T. 1997. A novel proline-rich motif present in ActA of Listeria monocytogenes and cytoskeletal proteins is the ligand for the EVH1 domain, a protein module present in the Ena/VASP family. EMBO J. 16: 5433-5444.

Patel, A.A. and Steitz, J.A. 2003. Splicing double: Insights from the second spliceosome. Nat. Rev. Mol. Cell. Biol. 4: 960-970.

Query, C.C., Moore, M.J., and Sharp, P.A. 1994. Branch nucleophile selection in pre-mRNA splicing: Evidence for the bulged duplex model. Genes \& Dev. 8: 587-597.

Query, C.C., Strobel, S.A., and Sharp, P.A. 1996. Three recognition events at the branch-site adenine. EMBO J. 15: 1392-1402.

Query, C.C., McCaw, P.S., and Sharp, P.A. 1997. A minimal spliceosomal complex A recognizes the branch site and polypyrimidine tract. Mol. Cell. Biol. 17: 2944-2953.

Sattler, M., Schleucher, J., and Griesinger, C. 1999. Heteronuclear multidimensional NMR experiments for the structure determination of proteins in solution employing pulsed field gradients. Prog. NMR Spectrosc. 34: 93-158.

Selenko, P., Gregorovic, G., Sprangers, R., Stier, G., Rhani, Z., Krämer, A., and Sattler, M. 2003. Structural basis for the molecular recognition between human splicing factors U2AF65 and SF1/mBBP. Mol. Cell 11: 965-976. 
Singh, R., Valcarcel, J., and Green, M.R. 1995. Distinct binding specificities and functions of higher eukaryotic polypyrimidine tractbinding proteins. Science 268: 1173-1176.

Staknis, D. and Reed, R. 1994. Direct interactions between pre-mRNA and six U2 small nuclear ribonucleoproteins during spliceosome assembly. Mol. Cell. Biol. 14: 2994-3005.

Will, C.L., Schneider, C., Reed, R., and Lührmann, R. 1999. Identification of both shared and distinct proteins in the major and minor spliceosomes. Science 284: 2003-2005.

Will, C.L., Schneider, C., MacMillan, A.M., Katopodis, N.F., Neubauer, G., Wilm, M., Lührmann, R., and Query, C.C. 2001. A novel U2 and U11/U12 snRNP protein that associates with the pre-mRNA branch site. EMBO J. 20: 4536-4546.
Will, C.L., Schneider, C., Hossbach, M., Urlaub, H., Rauhut, R., Elbashir, S., Tuschl, T., and Lührmann, R. 2004. The human 18S U11/U12 snRNP contains a set of novel proteins not found in the U2-dependent spliceosome. RNA 10: 929-941.

Wu, S., Romfo, C.M., Nilsen, T.W., and Green, M.R. 1999. Functional recognition of the $3^{\prime}$ splice site AG by the splicing factor U2AF35. Nature 402: 832-835.

Zamore, P.D., Patton, J.G., and Green, M.R. 1992. Cloning and domain structure of the mammalian splicing factor U2AF. Nature 355: 609-614.

Zorio, D.A. and Blumenthal, T. 1999. U2AF35 is encoded by an essential gene clustered in an operon with RRM/cyclophilin in Caenorhabditis elegans. RNA 5: 487-494. 

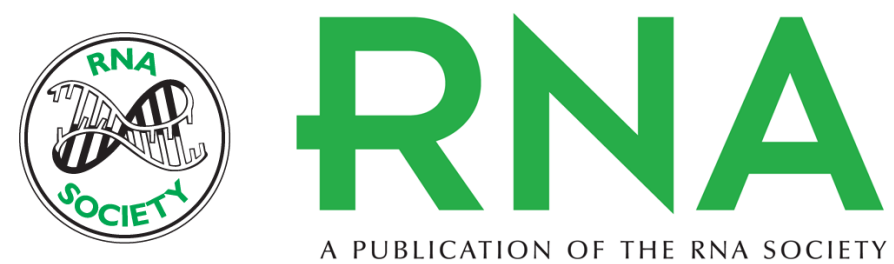

\section{Biochemical and NMR analyses of an SF3b155-p14-U2AF-RNA interaction network involved in branch point definition during pre-mRNA splicing}

ROBERTA SPADACCINI, ULRICH REIDT, OLEXANDR DYBKOV, et al.

RNA 2006 12: 410-425

References This article cites 39 articles, 20 of which can be accessed free at:

http://rnajournal.cshlp.org/content/12/3/410.full.html\#ref-list-1

License

Email Alerting Receive free email alerts when new articles cite this article - sign up in the box at the

Service top right corner of the article or click here. 